DEMOGRAPHIC RESEARCH

VOLUME 40, ARTICLE 41, PAGES 1167-1210

PUBLISHED 10 MAY 2019

http://www.demographic-research.org/Volumes/Vol40/41/

DOI: $10.4054 /$ DemRes.2019.40.41

Research Article

Impact of delayed effects on human old-age mortality

Andrea Verhulst

Hiram Beltrán-Sánchez

Alberto Palloni

(C) 2019 Verhulst, Beltrán-Sánchez \& Palloni.

This open-access work is published under the terms of the Creative Commons Attribution 3.0 Germany (CC BY 3.0 DE), which permits use, reproduction, and distribution in any medium, provided the original author(s) and source are given credit.

See https://creativecommons.org/licenses/by/3.0/de/legalcode 


\section{Contents}

$\begin{array}{llr}1 & \text { Introduction } & 1168\end{array}$

2 Background: Mechanisms for adult delayed effects 1169

3 Implication of delayed effects for human adult mortality patterns 1170

$4 \quad$ Predictions and conditions of observability 1171

$4.1 \quad$ Predictions $\quad 1172$

4.2 Conditions for the observability of delayed effects 1173

4.3 Implications of delayed effects: A summary 1175

$5 \quad$ Case study $\quad 1175$

5.1 Mortality decline in LAC 1176

$\begin{array}{lll}5.2 & \text { Classification of birth cohorts } & 1177\end{array}$

$6 \quad$ Materials, models, and methods $\quad 1179$

$\begin{array}{lll}6.1 & \text { Data } & 1179\end{array}$

$\begin{array}{lll}6.2 & \text { Models and methods } & 1180\end{array}$

$\begin{array}{llr}7 & \text { Results } & 1183\end{array}$

8 Summary of findings, limitations, and the road ahead 1197

$\begin{array}{lll}8.1 & \text { Summary of results } & 1197\end{array}$

$\begin{array}{lll}8.2 & 1197\end{array}$

$\begin{array}{llr}8.3 & \text { Future research } & 1199\end{array}$

9 Acknowledgments $\quad 1200$

$\begin{array}{lr}\text { References } & 1201\end{array}$

Appendix 1: Key results from a formal model of delayed effects 1205

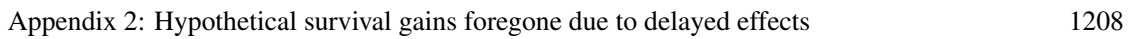




\title{
Impact of delayed effects on human old-age mortality ${ }^{1}$
}

\author{
Andrea Verhulst ${ }^{2}$ \\ Hiram Beltrán-Sánchez ${ }^{3}$ \\ Alberto Palloni ${ }^{4}$
}

\begin{abstract}
BACKGROUND

There is growing empirical evidence supporting theories of developmental origins of health and disease $(\mathrm{DOHaD})$. However, the implications of $\mathrm{DOHaD}$ conjectures for aggregate population patterns of human disease, disability, mortality, and aging are poorly understood.
\end{abstract}

\section{OBJECTIVE}

We empirically test two predictions derived from a formal model of aggregate populationlevel impacts of $\mathrm{DOHaD}$. This model predicts that populations potentially influenced by delayed effects should experience singularities in their adult mortality patterns that can be empirically detected from aggregate data.

\section{METHODS}

We test predictions using a large mortality database for populations in the Latin American and Caribbean (LAC) region, spanning nearly one hundred years of mortality history.

\section{RESULTS}

Results are consistent, within explicit bounds of uncertainty, with expected patterns. We find that younger cohorts in countries whose mortality decline starts more recently experience deceleration in survival gains at older ages, attenuation of the rate of aging at older ages, and a decline in the association between early childhood and adult mortality.

\section{CONCLUSIONS}

Results point to the importance of adverse early conditions for human longevity. Fu-

\footnotetext{
${ }^{1}$ All authors contributed equally.

2 Population Studies Center, University of Pennsylvania, Philadelphia, USA. Email: verhulst@ sas.upenn.edu.

${ }^{3}$ Department of Community Health Sciences, Fielding School of Public Health and California Center for Population Research, UCLA, Los Angeles, USA. Email: beltrans@ucla.edu.

${ }^{4}$ Labor and Population Unit, RAND Corporation and Center for Demography and Health of Aging, University of Wisconsin-Madison, USA. Email: palloni@ssc.wisc.edu.
} 
ture research should shed light on the impact on morbidity, disability, and healthy life expectancy.

\section{CONTRIBUTION}

To our knowledge this is the first time that implications of $\mathrm{DOHaD}$ conjectures for populations' mortality patterns are formulated precisely and empirically tested with aggregate population data.

\section{Introduction}

In the last decade or so, research guided by the Developmental Origins of Health and Disease $(\mathrm{DOHaD})$ paradigm and related theories has grown rapidly (Bateson and Gluckman 2011; Gluckman and Hanson 2005, 2006; Rosenfeld 2008). While the original idea of delayed adult effects of early childhood conditions has been around for quite some time and in very disparate strands of the literature (Derrick 2006; Frost 1939; Kermack, McEndrick, and McKinlay 1934; Preston and van de Walle 1978), it was Barker's work on "fetal programming" that provided the initial impetus for the creation of what is now a very active field of empirical research (Barker 1998, 2012; Hales and Baker 2001; Lucas 1991). Ecological and epidemiological studies, natural experiments, as well as animal studies under controlled conditions, provide an array of evidence supporting DOHaD's key predictions. However, the implications of $\mathrm{DOHaD}$ for aggregate population patterns of human health, disability, and mortality have been neither rigorously formulated nor empirically tested. In this paper we contribute to fill this vacuum. First, we rely on a formal model of relations between early conditions and adult health and mortality conjectured by $\mathrm{DOHaD}$ to derive a handful of predictions. Second, we use a long time series of cohort mortality in countries of the Latin American and Caribbean (LAC) region, whose populations, we argue, are primed to manifest the impact of early conditions, to test two of the model predictions.

The plan of the paper is as follows: In Section 2 we briefly review mechanisms posed by $\mathrm{DOHaD}$ and related theories. Section 3 describes implications of delayed effects for human adult mortality patterns. Section 4 presents predictions and conditions of observability. Section 5 describes selected characteristics of our case study. Section 6 reviews the data and models. Section 7 discusses results and draws inferences. In the final section we summarize, highlight limitations, and identify future lines of research. 


\section{Background: Mechanisms for adult delayed effects}

A diverse set of mechanisms could transform episodic or recurrent early exposures in utero, perinatally, and during infancy and early childhood into delayed impacts on adult illness, disability, and mortality. The mechanisms are associated with organ-specific embryo and fetal cell growth and differentiation (Bateson and Gluckman 2011; Gluckman and Hanson 2005, 2006), epigenetic changes (Gluckman, Buklijas, and Hanson 2016; Godfrey et al. 2007; Kuzawa and Eisenberg 2014; Meaney 2010), exposure to and contraction of early childhood diseases and sustained inflammation (Crimmins and Finch 2006; Elo and Preston 1992; Finch and Crimmins 2004; Fong 2000), and experiences with stressful conditions and environments (McEwen 1998; Meaney 2001, 2010). Furthermore, a large and influential body of empirical research documents the long-lasting impact of early nutritional status on adult health and mortality (Costa 2000; Fogel 2004; Scrimshaw 1997; Scrimshaw and SanGiovanni 1997). Finally, there is widespread empirical evidence demonstrating that more diffuse exposures, such as poverty and severe deprivation in infancy and early childhood, can also have lasting impacts (Bengtsson and Lindström 2012; Forsdahl 1987, 2002).

The mechanisms identified above are the focus of various strands of theories with unique histories and distinct disciplinary foundations. Different as they may be, however, they share an important trait as all invoke perturbations during critical periods of the development of a phenotype triggered by insults before conception, during embryonic and fetal life, perinatally, and across early stages of physical and cognitive growth. These early insults may then lead to disruptions in processes of organ growth, differentiation, and function; immune response; neurological development; metabolic regulation; and even the formation of adult preferences and behaviors. After variable but usually prolonged latency periods, the disruptions could manifest themselves as increased susceptibility to adult chronic illness.

This shared feature emphasized by multiple variants of $\mathrm{DOHaD}$ coexists with important differences that segregate them into distinct classes associated with different outcomes. For example, mechanisms that depend on epigenetic changes, such as methylation of $\mathrm{CpG}$ islands caused by nutrient deficiencies, disrupt metabolic function and are associated with child and adult obesity (Vickers 2014; Yajnik 2014). Others involve organ damage caused by an immune overresponse to bacteria, as in the case of acute rheumatic heart fever that increases the risk of adult heart valve stenosis (Sika-Paotonu et al. 1980). And yet others depend on misfiring of the HPA axis, an adaptation among some mammals to chronic stress, as when early abuse triggers adult depression, aggressiveness, and anxiety (Meaney 2010). The differences between these mechanisms range over a number of domains, including nature and timing of insults, critical and sensitive periods, chronic illnesses, critical ages after which the damage is manifested, and interactions between initial insults and individuals' lifetime exposure to different environments. 
Because these mechanisms are complex and their biological underpinnings are poorly understood, we are ill-equipped to trace precisely the pathways from exposure to final outcomes at the level of individuals, let alone discern different effects for entire populations. Thus, it is inevitable to embark on the initial investigation of population level impacts of delayed effects ignoring differences between mechanisms and focus only on their gross, overall impact on patterns of health and mortality. Although this is a simplification to circumvent lack of precise knowledge about the processes involved - not unlike omitting considerations of mediating pathways in causal analysis - it has an important payoff in that it enables us to identify the nature of processes that must be elucidated to understand long-term impacts irrespective of the mechanism conveying adult health manifestations. Given this simplification, and for the sake of terminological compactness, we adopt two abbreviations throughout. First, we use the term 'delayed effects' as shorthand for 'delayed adult health, disability, and mortality effects' associated with one or multiple mechanisms that link early conditions and adult diseases and mortality, irrespective of the nature of the chronic illness(es) involved. Second, we use the acronym DET (Delayed Effects Theories) as shorthand to refer to $\mathrm{DOHaD}$ and related theories, regardless of differences between the mechanisms that each of them prioritizes. We are mindful of the heterogeneous nature of this body of theories and, when precision is needed, we will abandon the shorthand.

\section{Implication of delayed effects for human adult mortality patterns}

Assume that one or a combination of DET theories conjecturing the existence of delayed effects associated with early exposures is correct. The question of interest for population health sciences is about the implications of different regimes of early exposures for population levels and patterns of adult health, disability, and mortality: If birth cohorts in different populations are exposed to heterogeneous regimes of early adverse conditions, how are these manifested in adult age patterns of morbidity, disability, and mortality? This question has been addressed before but at different levels of aggregation. Thus, there are well-known studies of adult effects of exposures to exceptional shocks among members of single birth cohorts, such as the survivors of famines (Lumey et al. 2012), and those exposed to natural disasters (Cao-Lei et al. 2014), and epidemics (Almond 2006). In addition, there is a rich body of epidemiological studies on the impact of more gradual, less acute, early experiences among individual members of single birth cohorts (Kuh and Ben-Shlomo 1997).

The approach we adopt in this paper is different from those above in that we focus on outcomes for entire populations. First, we formulate precisely the question posed at the outset by resorting to a formal model of DET that yields predictions about expected impacts of birth cohorts' early experiences on their adult mortality patterns. These pre- 
dictions are for entire populations, not for single individuals. Second, we focus on the historical experience of about $25-30$ birth cohorts in each of 18 populations in LAC. As a strategy to identify footprints of adverse early conditions on adult mortality patterns, we exploit heterogeneity of early childhood mortality to which these birth cohorts were exposed. The formal model helps us to define precisely distinct features of adult-age patterns of mortality that should be observed if DET theories are correct; that is, it specifies expected manifestations of a cohort's adverse early exposures on their adult mortality patterns. The model also identifies empirical conditions that must be met for an observer to be able to detect such impacts in commonly available empirical data. In the section below we review these predictions and identify the empirical conditions.

\section{Predictions and conditions of observability}

We seek answers to the following question: How do age patterns of adult mortality in populations influenced by early conditions differ from those in which early conditions have no bearing on adult mortality? To provide answers, we formulate a model that defines with precision the most important relations between early exposures and different cohorts' late mortality. These relations are simplified representations of multiple mechanisms proposed by DET theories and a summary of them is included in Appendix 1.5

An important feature of the model is the distinction between background and observed age patterns of mortality. A population's background mortality pattern is the set of age-specific death rates to which successive birth cohorts are exposed throughout their lives in the absence of delayed effects. It is a function of a fixed standard set of agespecific mortality rates that applies to all birth cohorts and a drift or mortality decline that reduces the level of mortality rates at all ages for successively born cohorts. In the absence of delayed effects, all birth cohorts should experience a fixed rate of senescence (rate of growth of adult mortality rates or Gompertz slope) and exhibit a fixed relation between mortality at early and older adult ages, both embedded in the background pattern of mortality.

A birth cohort's observed mortality pattern, on the other hand, is what the investigator would retrieve and measure from vital statistics. In the absence of delayed effects, background and observed age patterns of mortality should be identical. However, the presence of delayed effects will generate differences between background and observed mortality patterns, much as changes in the composition of a cohort by frailty induces differences between the baseline and the average, observed age pattern of mortality (Vaupel and Missov 2014). For delayed effects to be observable, however, the background mortality pattern must be disturbed by a mortality decline so that more recently born birth

\footnotetext{
${ }^{5}$ The full model is described elsewhere (Palloni and Beltrán-Sánchez 2016, 2017).
} 
cohorts experience better survival prospects at all ages, particularly in early childhood. Stationary mortality levels will not produce observable signs of delayed effects in aggregate mortality data even if individual members of birth cohorts are affected by them (Palloni and Beltrán-Sánchez 2016, 2017).

\subsection{Predictions}

We focus on two of the five predictions generated by the formal model.

\section{Prediction 1: On changes on the rate of adult mortality decline}

Under some conditions we describe in detail below, a secular mortality decline generates a growing influx of surviving individuals at all ages who are more susceptible to express delayed effects after attaining some (adult) critical age. As a consequence of this, the observed pace of adult mortality decline of successive birth cohorts will decelerate and drop below the rate of background mortality decline. ${ }^{6}$

\section{Prediction 2: On distortions of the age pattern of mortality}

If and when the secular mortality decline generates a growing influx of survivors primed to expressed delayed effects, the relation between early childhood and adult mortality rates will change as follows:

(2.1) The observed within-cohort association between child mortality and adult mortality will decline in absolute value even if the association in the background mortality regime remains invariant.

(2.2) The observed within-cohort association between child mortality and the adult mortality slope (rate of senescence of the age pattern of mortality) will be attenuated and converge to zero among the more recently born cohorts even though the older adult background mortality pattern remains invariant.

An additional implication of the model (prediction 3) that helps us leverage data to test predictions 1, 2.1, and 2.2 is the following: Differences between observed and expected patterns implied by these predictions must be more pronounced in populations whose mortality decline is more rapid, more strongly dependent on survival gains at very young ages, and driven by reduction of fatality rates of communicable diseases rather than

\footnotetext{
${ }^{6}$ Note that the prediction refers to the rate of adult mortality decline only, not to the rate of decline of mortality at younger ages which could remain unaffected. This is a key difference between our model and a classic model with unobserved heterogeneity (Palloni and Beltrán-Sánchez 2016, 2017).
} 
by amelioration of standards of living, better maternal health, and improved maternal and child nutrition.

\subsection{Conditions for the observability of delayed effects}

The manifestation of delayed effects on mortality patterns - differences between observed and background mortality - will be detectable only if some conditions are met. The first three conditions are 'hard' in that, when not met, there will be no observable traces of delayed effects on adult mortality patterns. The last condition is 'soft' and, if not met, the signals of delayed effects will be dimmer but not necessarily absent.

(1) Survival to critical ages:

A nontrivial fraction of members of a birth cohort who experience early insults survive beyond some critical age $Y_{1}$ after which manifestations of the original damage begin to unfold, e.g., if $Y_{1}$ is too high, there will be weak or no observable delayed effects.

(2) Growing fraction of infant and children surviving to critical ages:

The (background) secular mortality decline is sustained by improvements in infant and child survival that increase the fraction of successive cohorts surviving to critical ages, e.g., if mortality improvements influence only older adult mortality, no delayed effects will be observed in aggregate data. Some types of child mortality decline are stronger promoters of increased adult susceptibility to delayed effects than others. Thus, a mortality decline whose root cause is reductions of fatality rates of communicable diseases, more so than improvements in nutritional status or declining exposure to diseases, promotes increases in the adult prevalence of individuals who were exposed to early nutritional deprivation and/or to repeated bouts of illnesses. These types of secular mortality declines are characteristic of post1950 low- and middle-income countries in general and LAC in particular (Palloni and Pinto 2011; Preston 1980).

(3) Moderately sized excess fatality rates:

Delayed effects must be associated with higher than average morbidity or mortality risks for a broad range of illnesses and conditions with nontrivial impacts.

(4) Neutral improvements of medical technology:

The beneficial effects related to mortality (morbidity) of medical improvements adopted between the time of onset of each birth cohort's early experiences and the time at which its members attain the critical age $Y_{1}$ fail to offset excess mortality risks due to chronic illnesses associated with delayed effects.

A schematic summary of these conditions is in Table 1. The first two conditions are straightforward. Adult delayed effects will only be observable if a significant fraction of 
those who are most susceptible to express them survive beyond ages at which delayed effects manifest themselves.

Because it is likely that individuals most exposed to adverse early conditions are those who also experience more elevated mortality risks than the average, the condition requires that the excess mortality that these subpopulations experience (perhaps in adolescence or later but before critical ages) is not offset by gains associated with the secular mortality decline. Only when there is a nontrivial offsetting effect will we observe an increase in the proportional contribution of individuals most exposed to adverse early conditions to the population surviving past a critical age.

The second condition requires that successive birth cohorts experience gradual increases in the fraction of individuals most susceptible to express delayed effects who survive to critical ages. The third condition states that delayed effects are irrelevant if they are expressed only via rare diseases and disorders or by illnesses with low fatality rates. Finally, the fourth condition requires that gains in adult survival due to medical improvements that reduce fatality rates of chronic illnesses associated with delayed effects should not swamp the expected excess mortality triggered by them. While the first three conditions are likely to be met in populations that experienced secular mortality declines such as those in LAC countries, the last one is less so. As a consequence, unless the impacts of medical improvements are accounted for, estimates of the magnitude of delayed effects on mortality will always be understated. ${ }^{7}$

\section{Table 1: Conditions for observability of delayed effects on adult mortality patterns}

\begin{tabular}{lll}
\hline Condition & Expected effect of the condition \\
\hline 1. Survival to critical ages is nontrivial & $\begin{array}{l}\text { The probabilities of surviving to critical ages must be nontrivial or, } \\
\text { equivalently, the critical ages cannot exceed certain ages for which } \\
\text { survival probabilities are very low. }\end{array}$ \\
2. Nature of secular mortality decline & $\begin{array}{l}\text { Successive increases in the fraction of adult population who survived } \\
\text { past critical ages and experienced early deprivation. } \\
\text { 3. Magnitude of adult fatality rates }\end{array}$ & $\begin{array}{l}\text { The fatality rates of chronic illnesses associated with deprivations } \\
\text { experienced early in life are nontrivial. } \\
\text { The magnitude of reduction in fatality rates associated with adult } \\
\text { chronic illnesses affected by early conditions is not large enough to } \\
\text { offset increases due to a larger influx of population susceptible to } \\
\text { them by virtue of their earlier experience. }\end{array}$ \\
\hline
\end{tabular}

\footnotetext{
${ }^{7}$ It should be noted that the fourth condition applies only to mortality. If one is assessing the impact of early conditions on the prevalence of chronic illnesses rather than fatality rates, the condition does not apply. For example, it is known that poor nutrition in utero may prime individuals for adult metabolic disorders. If the excess mortality implied by some of these disorders (e.g., T2D) is offset by medical improvements, the impact of an increased flow of individuals who experienced in utero deprivation will not be observable. But, regardless of how beneficial medical technologies that reduce T2D fatality rates are, the prevalence of T2D will increase.
} 


\subsection{Implications of delayed effects: A summary}

The discussion above suggests that in populations susceptible to delayed effects that meet a handful of conditions, cohorts' adult mortality patterns may experience deformations (Fridlizius 1989). When mortality decline occurs in a population primed for delayed effects (e.g., with a significant pool of susceptible individuals), the potential exists for large, albeit lagged, increases of the fraction of individuals surviving past the critical age $Y_{1}$ who are scarred by adverse early experiences. To the extent that these experiences manifest into adult mortality excesses, they will result in reductions of the rate of change of adult mortality for the corresponding birth cohorts. This could halt or slow down improvements in adult mortality even if background mortality is declining at a constant rate. In addition, the rate of age-dependent growth of older adult mortality will change over time even if the age pattern of background mortality is invariant. In the very long run, when the effects of improvements of mortality before critical ages run their course, these deformations of cohort mortality will subside and a new background mortality pattern with no memory of past experiences will be established.

The expected deformations of birth cohorts' adult mortality patterns described above are analogous to those produced by changes in composition by frailty in the absence of delayed effects. The difference between the two regimes is that while changes in composition by frailty with no delayed effects can never reverse a mortality decline and leaves imprints in the rate of decline of mortality rates at all ages, the impact of delayed effects could reverse a mortality decline but will do so only at ages older than the critical age.

Finally, although we do not investigate it in this paper, the impacts alluded to above may be amplified if, as is the case in most low- to middle-income countries, there are rapid and profound dietary and lifestyle changes that increase discordance between embryonic, uterine, and post-birth environments (Bateson et al. 2004; Bateson and Gluckman 2011). Birth cohorts who experience such discordance could be exposed to more severe adult expression of delayed effects than when there are long time lags between the experience of deleterious pre-conception, embryonic, or fetal environments and profound shifts in post-natal conditions.

\section{Case study}

We test predictions using the mortality experiences of countries of the Latin American and Caribbean (LAC) region during the period 1900-2015. The main attributes of the mortality decline in the LAC region potentiate the expression of delayed effects and provide some opportunities to detect evidence of perturbations of cohorts' mortality patterns described in predictions $1,2.1$, and 2.2. 


\subsection{Mortality decline in LAC}

Two features of mortality decline in LAC are of interest. First, it was fast, and its initial driver was a disproportionate reduction of early childhood mortality. As Figure 1 shows, the contours of child mortality decline in three groups of LAC countries: forerunners, intermediate, and laggards (see definitions below). Second, the bulk of the decline that affects cohorts born between 1935 and 1970 is associated with the post-1935 wide dissemination of sulfas, penicillin, antibiotics, and eradication of parasitic diseases. Any change in mortality before the widespread dissemination of sulfas and antibiotics (roughly before 1935/1940) must be associated with either improvements in standards of living (housing, nutrition), advances in infrastructure (water, sewage, electricity), or massive public health interventions (eradication campaigns). These changes improved survival by changing maternal and fetal nutrition and by diminishing the risks of exposure to and contraction of infectious and parasitic diseases. Cohorts born after 1935 in countries that had not yet experienced these structural changes benefitted mostly from survival gains associated with diffusion of chemotherapies. Of lesser importance were changes in conditions that influenced maternal and fetal nutrition or the opportunities for exposure to infectious and parasitic diseases. Thus, being born after 1935 is tantamount to being exposed to a 'treatment' that could result in increases in the fraction of a birth cohort's adult survivors who are more susceptible to expressing delayed effects. This change occured because these cohorts benefitted from survival gains even if their exposure to adverse conditions (early nutrition, maternal health, diseases, ecology) remained largely unchanged. Previous research suggests that a fraction exceeding $40-60 \%$ of the mortality decline that followed the end of World War II in LAC is due to the dissemination of new medical technologies that first reduced the fatality rates of communicable diseases and then helped to attenuate exposure to them (vaccination and eradication campaigns) (Palloni and Pinto 2011; Palloni and Wyrick 1981; Preston 1980).

Timing of birth (pre- and post-1935) is an appealing but very blunt indicator of a cohort's potential to manifest delayed effects. A more useful indicator can be constructed by combining the timing of birth with the cohort's country of origin. This is because LAC countries experienced two very different regimes of mortality decline. A group of countries ('forerunners') began an early mortality decline that was fueled throughout, except perhaps in late stages after 1970, by socioeconomic improvements, including amelioration of standards of living, infrastructure, and sanitation. In contrast, the mortality decline in a second group of countries ('laggards') begins much later and, except at its tail end, is mostly driven by dissemination of antibiotics and eradication campaigns. All post-1950 birth cohorts are influenced to some degree by the advent of new medical technologies, but those born in laggard countries are much more influenced than those born in forerunner countries (Palloni, Beltrán-Sánchez, and Pinto 2016). Thus, combining timing of 
birth and country of origin leads to a more useful, albeit still primitive, indicator of a cohort's potential to manifest delayed effects.

Figure 1: Time trends in childhood mortality rates $\left({ }_{5} q_{0}\right)$ for Latin American countries by timing of onset of mortality decline

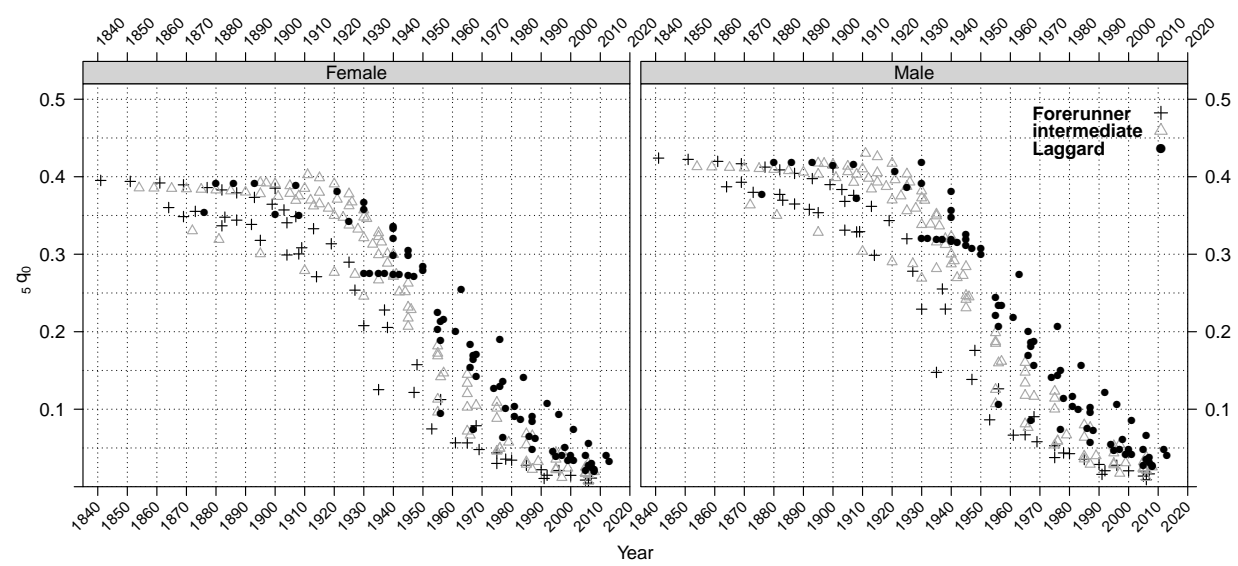

Source: LAMBdA (http://www.ssc.wisc.edu/cdha/latinmortality).

\subsection{Classification of birth cohorts}

Following the above discussion and to facilitate testing of the two global predictions, we classify birth cohorts according to two criteria. The first criterion is the cohort's year of birth. Child survival of cohorts born early in the century (before 1935) could not possibly have benefited from factors other than improved nutrition and sanitation and are less likely to manifest delayed effects. Instead, cohorts born more recently, particularly after the end World War II, are more likely to have experienced substantial gains due to medical innovations, in some cases in combination with improvements in standards of living. The second criterion is whether or not a cohort's country of birth experiences the onset of a secular mortality decline before or after the widespread application of medical technologies (circa 1935). This is a device to distinguish epidemiological regimes where it was possible to attain gains in survival through improvements in standards of living (forerunner countries whose mortality decline began circa 1925-1935) from those where the onset of mortality decline followed the dissemination of new medical technologies (laggard countries whose mortality decline began after 1945-1950). The former countries' mortality decline is more gradual and less dependent on improvements in childhood 
survival. The latter countries' mortality decline is sharper and tightly connected to reductions of infant and child mortality. These two criteria - a cohort's timing of birth and the country's timing of the onset of mortality decline - lead to a simple classification of birth cohorts under observation, portrayed in Figure 2. Cohorts in quadrants A and B include forerunner countries $(N=9)$ that begin their mortality decline early in the century, certainly before 1935 (Figure 1); countries in quadrants $C$ and D include laggard countries $(N=9)$ whose mortality decline begins in earnest only after 1950 . The main contrast is between birth cohorts in Quadrant A and Quadrant D. A second, albeit weaker, contrast is between birth cohorts in Quadrants C and D. This classification is a crude tool but offers us some leverage to identify birth cohorts with higher (lower) 'propensity' to experience the imprints of delayed effects.

Figure 2: Classification of birth cohorts by year of birth and country's year of onset of mortality decline (axis not to scale)

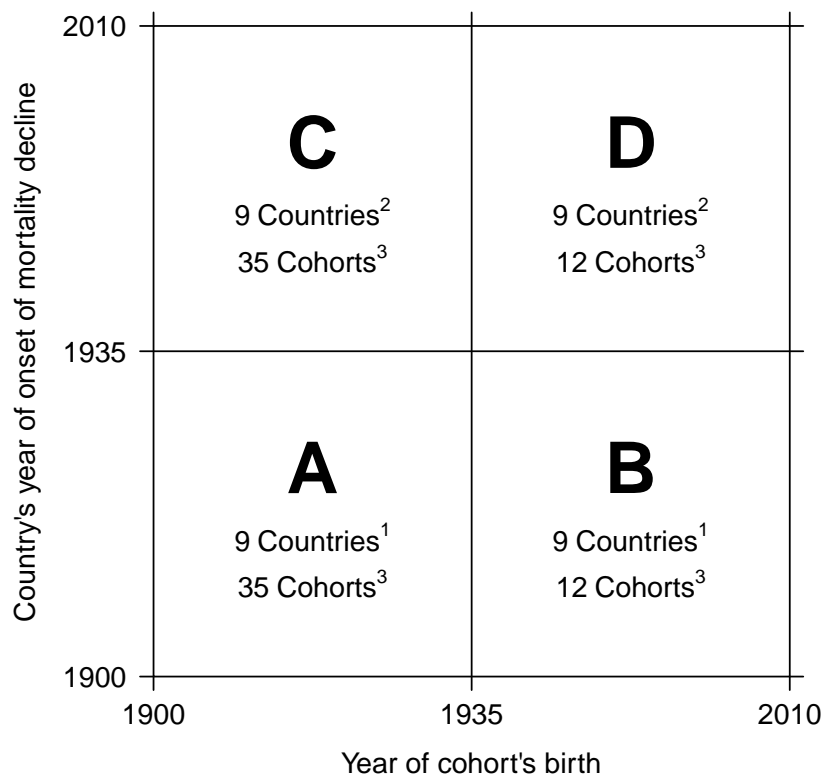

Note: 1. Argentina, Chile, Colombia, Costa Rica, Cuba, Mexico, Panama, Uruguay, Venezuela. 2. Brazil, Dominican Republic, Ecuador, El Salvador, Guatemala, Honduras, Nicaragua, Paraguay, Peru. 3. Birth cohorts belong to 18 countries, and in each quadrant, we include cohorts for which we observe mortality before age 65 . 


\section{Materials, models, and methods}

\subsection{Data}

We use the Latin American Mortality Database, LAMBdA (http://www.ssc.wisc.edu/ cdha/latinmortality), which documents the history of mortality in LAC countries after independence. The data is for the period between 1848 and 2014 and contains about 500 life tables. The information to compute life tables for the period 1930-2010 are agespecific death rates adjusted for relative completeness of death registration as well as for adult-age overstatement. These life tables are available yearly. Life tables for most countries before 1930 are based on the application of generalized stable population to partial vital statistics and census information. Yearly life tables for the period before 1950 are available for a handful of countries only $(N=10)$. In all other cases we estimate life tables every five or ten years. To fill in yearly missing data before 1930, we use splines with three and four knots fitted to single age-specific mortality rates. Merging all the data results in a set of calendar year and gender-specific (period) life tables in single-year ages for the period 1870-2010. Cohort life tables, starting with those born in 1900, are computed by chaining together age-specific rates of period life tables. Life tables for birth cohorts born after 1900 contain variable right censoring of mortality experiences: If we close the life tables with the open age group 85+, there is no censoring for birth cohorts born before 1925 and maximum censoring among birth cohorts born after 1965 whose adult mortality experience is truncated at age 45 . To graphically represent birth cohorts and the adult experience included in our analysis, Figure 3 shows a Lexis diagram of cohorts' life courses captured in this study. Cohorts born after 1965 offer minimal coverage of adult mortality and are ignored. Cohorts born after 1940 and before 1965 are right censored, and we only observe mortality up to some upper age limit, 70 to 75 for those born in 1935 and 40 to 45 for those born in 1965. Limited observability of adult mortality rate is, of course, an important limitation of our empirical analysis.

We also use the Human Mortality Database (HMD). We select five populations (England and Wales, France, Italy, Norway, and Sweden) and perform placebo tests to gauge the relative importance of delayed effects in the LAC region in contrast to populations of Europe and North America. 
Figure 3: Lexis diagram depicting cohorts used in the study indicating adult mortality in complete (darker section) and incomplete (right-censored) cohorts and their corresponding cohort child mortality

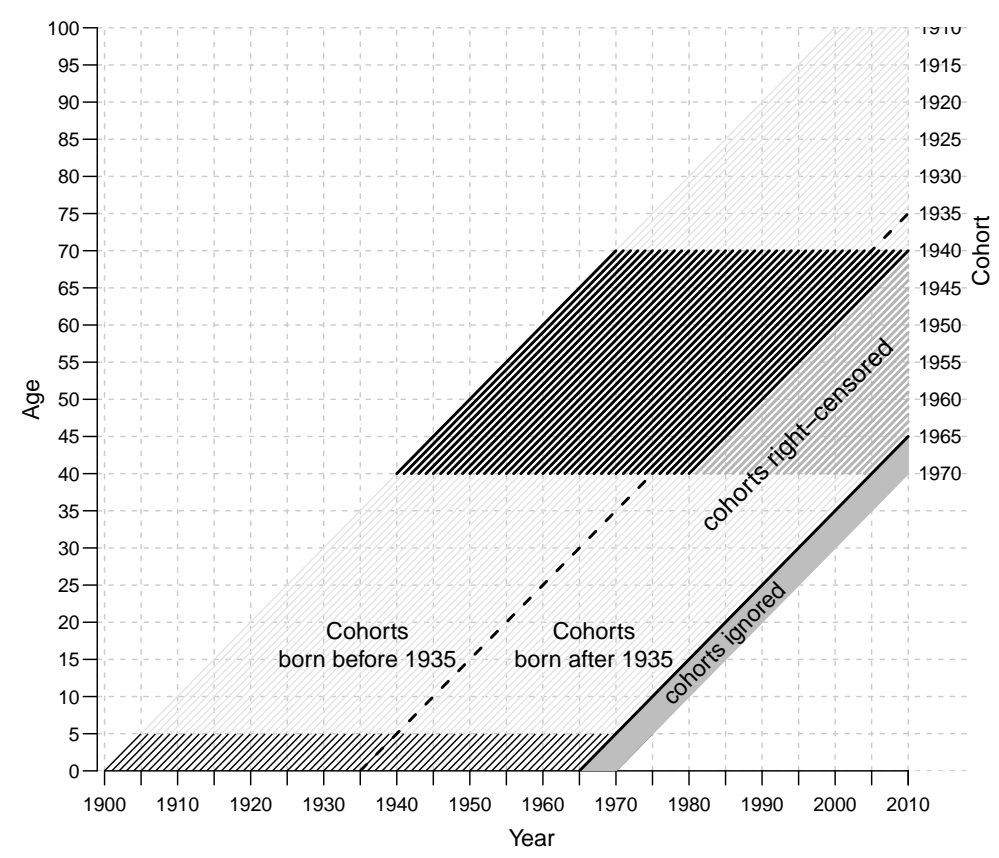

\subsection{Models and methods}

\section{Prediction 1}

One way to test Prediction 1, is to contrast rates of change of mortality rates for successive births cohorts at selected adult ages (40-59, 40-64, and 40-69). We expect that the rate of decline in countries most susceptible to experience delayed effects will decline for younger cohorts, particularly among those born after 1935. By the same token, birth cohorts born after 1935 or so should experience stronger deceleration than cohorts born before 1935 . 


\section{Prediction 2.1}

To test the prediction 2.1, we first estimate parameters of the relation between changes in cohorts' child mortality at young ages and changes in their adult mortality. Graphs of these relations are in Figure S-1 in Supplemental Material I. We use two approaches: First, we estimate a linear regression model for the log of cohorts' adult mortality rates at ages $(x, x+k), \mathbf{M}_{i}(x, t)$, as a function of the $\log$ of their child mortality rates (ages 0 to 4), $\mathbf{M}_{i}(0, t)$ :

$$
\ln \left(\mathbf{M}_{i}(x, t)\right)=\alpha_{i}+\beta_{i} * \ln \left(\mathbf{M}_{i}(0, t)\right)+\epsilon_{i}
$$

where $t$ is the calendar year of birth of the cohort and $i$ is an index for country. The regression coefficient $\beta$ is the proportionate change in adult mortality of a cohort given a unit-proportionate change in its child mortality. In populations with a secular mortality decline where changes are proportionate at all ages, the value of $\beta$ should be identical for all cohorts. Differences across populations will reflect heterogeneity in the pace of mortality decline. However, when there are delayed effects for some cohorts but not for others, the regime in Equation (1a) will systematically differ across cohorts (and populations). In particular, we expect that estimates of $\beta$ should be lower in cohorts primed to express delayed effects. To verify that this is the case, we estimate country-specific parameters of model $1 \mathrm{a}$ for three adult age groups (40-59, 40-64, and 40-69), and we do so separately for cohorts born before and after the year 1935. Prediction 2.1 points to strong contrasts between estimates of the slope parameter in the younger and older cohorts, on one hand, and in forerunner and laggard countries, on the other.

We use a second approach that consists of estimating a similar model to Equation (1a) using a mixed model framework (multilevel). Models are estimated separately by age group, sex, and stage of demographic transition (e.g., forerunner and laggard):

Level 1:

$$
\ln \left(\mathbf{M}_{i j}(x, t)\right)=a_{0 j}+\beta_{1 j} \ln \left(\mathbf{M}_{i j}(0, t)\right)+r_{i j}
$$

Level 2:

$$
\begin{aligned}
& a_{0 j}=\gamma_{00}+\gamma_{01}\left(\text { Born after 1935) }+u_{0 j}\right. \\
& \beta_{1 j}=\gamma_{10}+\gamma_{11}\left(\text { Born after 1935) }+u_{1 j}\right.
\end{aligned}
$$

where: $i$ is cohort and $j$ is country, $r_{i j}$ is a normally distributed error with homogeneous variance across countries, $a_{0 j}$ and $\beta_{1 j}$ vary across countries in level-2, $\gamma_{00}$ represents the mean $\log$ mortality rate for cohorts born before $1935, \gamma_{01}$ represents the difference in the mean $\log$ mortality rate between cohorts born before and after $1935, \gamma_{10}$ represents the 
mean proportionate change in adult mortality for cohorts born before 1935 given a unitproportionate change in child mortality, and $\gamma_{11}$ represents the difference in the mean proportionate change in adult mortality between cohorts born before and after 1935 given a unit-proportionate change in child mortality, $u_{0 j}$ and $u_{1 j}$ are multivariate normally distributed with means of zero and conditional variance-covariance components after controlling for cohort's year of birth; in other words, they represent residual dispersion in $a_{0 j}$ and $\beta_{1 j}$ after controlling for cohort's year of birth.

Of particular importance for prediction 2.1 is the parameter $\gamma_{11}$, a measure of differences in proportionate changes in adult mortality between cohorts.

\section{Prediction 2.2}

To falsify prediction 2.2, we implement two tests. The first rests on estimation of the following model:

$$
\ln \left(\mathrm{GS}_{i}(t)\right)=\lambda_{i}+\theta_{i} * \ln \left(\mathbf{M}_{i}(0, t)\right)+\sigma_{i}
$$

where $\mathrm{GS}_{i}(t)$ and $\mathrm{M}_{i}(0, t)$ are, respectively, the Gompertz slope and child mortality rates for a cohort born in year $t$ in population in country $i$. Model 2 is estimated for each country and separately for cohorts born before and after 1935. Prediction 2.2 suggests that estimates of the slope in model 2 will be attenuated in more recently born cohorts, particularly in laggard countries.

The second test depends on the following consideration: Suppose we do indeed observe a reduction in slopes in model 2 in LAC countries. It may be the case that such reduction is induced by conditions other than by the presence of delayed effects, perhaps related to factors that drive most secular mortality declines, and are omitted from the model. If this were the case we should observe a similar pattern in populations that also undergo secular mortality declines but where we do not expect delayed effects to be influential. Most countries in Western Europe experienced a mortality decline with an onset circa 1850, long before the introduction of medical technology. It was gradual and driven by changes in sanitation, housing, and - most importantly - improvements in nutritional status. In these cases, we would expect that estimates of model 2 reveal similar shifts to those observed in LAC but only because they are the result of other features of a secular mortality decline, not the consequence of delayed effects. Otherwise, the relations estimated for birth cohorts in these European populations should yield higher predicted values of $\mathrm{GS}(\mathrm{t})$ for cohorts experiencing a given value of $\mathrm{M}(0, t)$ than do parameter estimates in LAC for cohorts with identical values of $\mathbf{M}(0, t)$. The placebo test consists then of computing values of $\mathrm{GS}_{i}(t)$ in LAC birth cohorts predicted from model 2 but with parameters estimated in countries of Northern and Western Europe. To carry out this test, we estimate model 2 using mortality data for the five HMD countries mentioned before. 
Table 2: $\quad$ Number of cases where the rate of change of age specific mortality rates for a cohort are lower than for the preceding cohort (deceleration) for ages 40-59, 40-64, and 40-69

\begin{tabular}{|c|c|c|c|c|c|c|}
\hline \multirow[t]{3}{*}{ Female } & \multirow{2}{*}{\multicolumn{3}{|c|}{ Born before 1935}} & \multirow{2}{*}{\multicolumn{3}{|c|}{ Born after 1935}} \\
\hline & & & & & & \\
\hline & Deceleration & $\mathrm{n}$ & $\%$ & Deceleration & $\mathrm{n}$ & $\%$ \\
\hline \multicolumn{7}{|c|}{ Forerunners } \\
\hline $40-59$ & 143 & 273 & 52.38 & 71 & 135 & 52.59 \\
\hline $40-64$ & 130 & 273 & 47.62 & 53 & 90 & 58.89 \\
\hline $40-69$ & 128 & 273 & 46.89 & 24 & 45 & 53.33 \\
\hline \multicolumn{7}{|c|}{ Laggards } \\
\hline $40-59$ & 60 & 126 & 47.62 & 51 & 88 & 57.95 \\
\hline $40-64$ & 68 & 126 & 53.97 & 37 & 56 & 66.07 \\
\hline $40-69$ & 64 & 126 & 50.79 & 17 & 26 & 65.38 \\
\hline \multicolumn{7}{|l|}{ Male } \\
\hline & \multicolumn{3}{|c|}{ Born before 1935} & \multicolumn{3}{|c|}{ Born after 1935} \\
\hline & Deceleration & $n$ & $\%$ & Deceleration & $n$ & $\%$ \\
\hline \multicolumn{7}{|c|}{ Forerunners } \\
\hline $40-59$ & 140 & 273 & 51.28 & 77 & 135 & 57.04 \\
\hline $40-64$ & 131 & 273 & 47.99 & 51 & 90 & 56.67 \\
\hline $40-69$ & 134 & 273 & 49.08 & 30 & 45 & 66.67 \\
\hline \multicolumn{7}{|c|}{ Laggards } \\
\hline $40-59$ & 70 & 126 & 55.56 & 43 & 88 & 48.86 \\
\hline $40-64$ & 63 & 126 & 50.00 & 35 & 56 & 62.50 \\
\hline $40-69$ & 63 & 126 & 50.00 & 15 & 26 & 57.69 \\
\hline
\end{tabular}

\section{Results}

\section{Prediction 1}

We test Prediction 1 using rates of change of mortality rates for successive births cohorts at adult ages (40-59, 40-64, and 40-69). Table 2 displays the frequency of cases that agree with the prediction (that is cases where the rate of change of age-specific mortality rates at adult ages for a birth cohort are lower than for the preceding cohort). With one exception, (males at ages 40-59), birth cohorts born after 1935 exhibit stronger deceleration in the rates of change of mortality rates than those born before 1935. In addition, the magnitude of deceleration in cohorts born in laggard countries is larger than observed in forerunners. For example, in about two-thirds (66\%) of cases corresponding to female birth cohorts born after 1935 experienced deceleration of the rate of change of mortality rates at ages 40-64. The figure for those born before 1935 is 54\%. Moreover, and as expected, the fraction of cases that conform with the prediction increases with age. For 
example, a comparison of changes in mortality rates in the age group 40-64 against those in the age group 40-59, consistently reveals a higher fraction of cases with deceleration in cohorts born after 1935. In addition, the observed differences are larger in cohorts born after 1935. These patterns are less consistent for the age group 40-69, but the number of uncensored birth cohorts that enter into the calculations is, in this case, quite low and comparisons accordingly noisier. In sum, although the statistical power of the test is admittedly modest, the observed patterns agree with all expectations.

\section{Prediction 2.1}

According to prediction 2.1 the regression coefficients of model 1a are expected to be of lower magnitude for the more recently born cohorts and for populations more likely to express delayed effects. Similarly, $\gamma_{11}$ in model $1 \mathrm{~b}$ is expected to be negative - implying lower magnitude among recently born cohorts. To estimate models $1 \mathrm{a}$ and $1 \mathrm{~b}$ while maintaining acceptable sample sizes, we choose adult age groups 40-59, 40-64, and 4069. This choice is not optimal to assess the full-blown impact on adult mortality since, due to right censoring of cohorts' mortality experiences, we only capture effects in the youngest part of their adult life, when morbidity and mortality risks are less severe. If the model is correct, this choice of age groups will lead to understate the effects of interest.

Table 3 displays estimates of model 1 using the adult age group 40-64. Similar inferences can be drawn from results for age groups 40-59 and 40-69 included in Tables S-1 in Supplemental Material I. Table 4 displays estimates of the multilevel model, for age group 40-64; similar inferences can be drawn from results for age groups 40-59 and 40-69 in Tables S-2 in Supplemental Material I. Figure 4 is a box plot of estimated regression coefficients for the age group 40-64 by sex, type of country, and timing of the cohorts' birth (see Figures S-2 in Supplement Material I for box plots of coefficients using other age groups). 
Figure 4: Box plots of estimated coefficients of the regression $\ln \left(\mathbf{M}_{i}(40,64)\right)=\alpha_{i}+\beta_{i} * \ln \left(\mathbf{M}_{i}(0,4)\right)+\epsilon_{i}$ by country $(i)$, sex, and cohort year of birth; $M(40,64)$ and $M(0,4)$ correspond to cohort mortality rates at ages 40-64 and 0-4

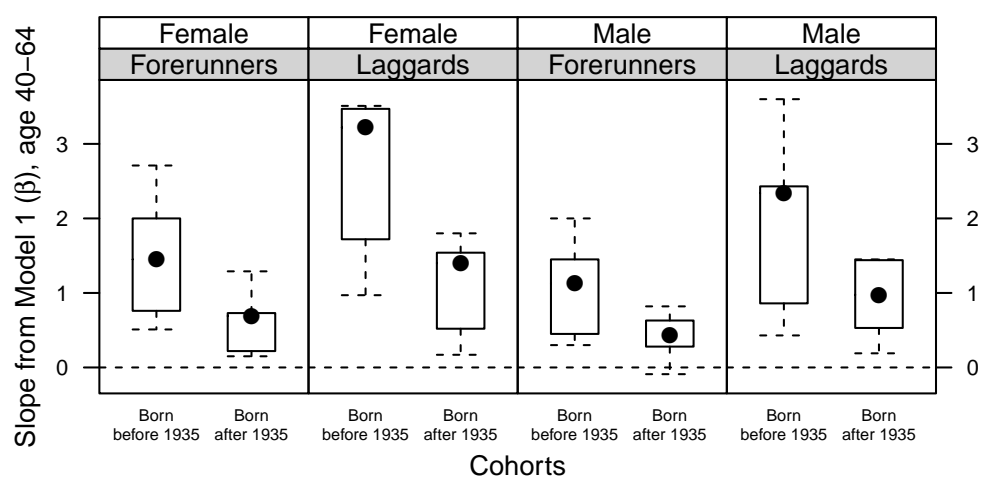

With one exception (Cuban males born after 1935) the estimates in Table 3 are all positive confirming a finding in high income countries, namely, that a cohort's relative gains (losses) in early child survival tend to be preserved or augmented at older adult ages (Finch and Crimmins 2004). Furthermore, with two exceptions (males in Argentina and Uruguay), the magnitude of the regression coefficients for the more recent cohorts (born after 1935) declines over time as expected and, in some cases, substantially so. Results from model $1 \mathrm{~b}$ in Table 4 provide additional supporting evidence as they confirm a statistically significant decline in the regression coefficients for cohorts born after 1935 with larger reductions among cohorts in laggard countries.

What practical implications does the generalized decrease in slopes among younger birth cohorts have? An appealing interpretation is the following: Since the slope in model $1 \mathrm{a}$ is an estimate of the expected change in a birth cohort's adult mortality conditional on the cohort's change in child mortality, we can translate (approximately) the estimate of the slope into gains in years of life expectancy at age 60 implied by the cohort's child mortality changes. Cohorts endowed with smaller slopes are expected to experience smaller gains in life expectancy at age 60 than cohorts with higher slopes for a given change in their child mortality. In other words, birth cohorts exposed to delayed effects that reduce the magnitude of the slopes will experience 'foregone' gains of life expectancy at age 60 . The formal justification for this computation and the expressions used to generate estimates and 95\% CI's are in the Appendix 2. Table 5 displays proportionate years of life expectancy at age 60 that cohorts born before and after 1935 would gain over a period of 20 years given a decline of $1 \%$ per year in their child mortality (Columns 1 and 2). Column 3 displays the ratios of values for the younger (Column 2) to the older (Column 1), 
Column 4 shows the 95\% CI (approximates), Column 5 displays years of life expectancy gains foregone, and Column 6 includes the corresponding 95\% CI (approximated). For example, in Peru the ratio for males is 0.68 (1.361/2.002), indicating that the younger cohorts experience gains in life expectancy at age 60 about $68 \%$ as large as the gains in the older cohorts given identical changes in early childhood mortality rates. Figure 5 is a box plot of estimated years of life expectancy at age 60 foregone among younger cohorts (Column 5 of Table 5) by cohort, sex, and type of country. To place these quantities in perspective, consider the following: The average LAC's female life expectancy at age 60 in the year 2000 was of the order of 18 years and, according to projections, it is expected to increase to about 21 years in the year 2020, a gain of about 3 years (17\%) (United Nations 2017). The more recent female birth cohorts in Peru would only gain approximately 1.92 of these three years or, equivalently, would experience 1.08 years of gains of the projected total (Table 5, column 5). This is about $6 \%$ of the baseline life expectancy at age 60 in the year 2000. It is worth noting that the order of magnitude of these estimates is somewhat lower than estimates of mortality penalties associated with delayed effects obtained with completely different procedures by other researchers (Palloni and Souza 2013).

Figure 5: Box plots of estimated years of life expectancy at age 60 foregone for cohorts born after 1935

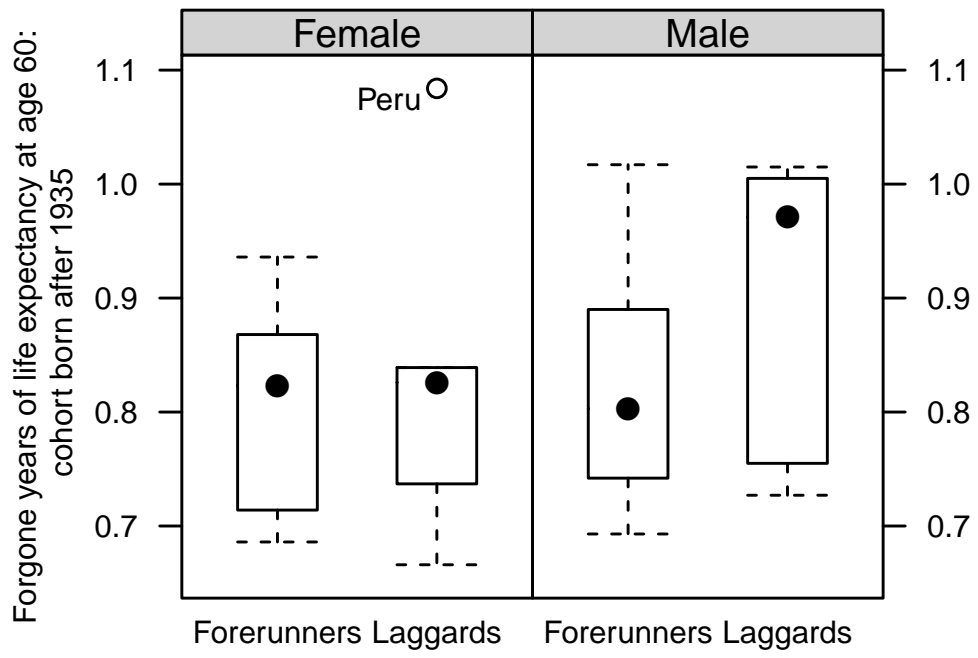

There are two problems with this evidence. The first is that prediction 2.1 is not perfectly satisfied. According to this prediction, birth cohorts in countries whose mortality decline started earlier should manifest the expected pattern - discordance of gains 
between older and younger cohorts - more weakly than do birth cohorts in laggard countries. However, the results from the multilevel model corroborate this expectation as the parameter $\gamma_{11}$ is always smaller in forerunner countries except in a few cases for the age group 60-69. Also, the years of life expectancy gain foregone by younger cohorts are indeed larger in laggard countries even though males appear to be more affected than females (Figure 5).

The second, and deeper, problem is one of interpretation: While the observed discordance between older and younger birth cohorts could be a result of delayed effects, other mechanisms may also account for the finding. We return to this issue latter in the paper. 
Verhulst, Beltrán-Sánchez \& Palloni: Impact of delayed effects on human old-age mortality

Table 3: $\quad$ Estimated coefficients of the regression

$\ln \left(\mathbf{M}_{i}(40,64)\right)=\alpha_{i}+\beta_{i} * \ln \left(\mathbf{M}_{i}(0,4)\right)+\epsilon_{i}$ by country $(i)$, sex, and cohort year of birth. $M(40,64)$ and $M(0,4)$ correspond to cohort mortality rates at ages 40-64 and 0-4

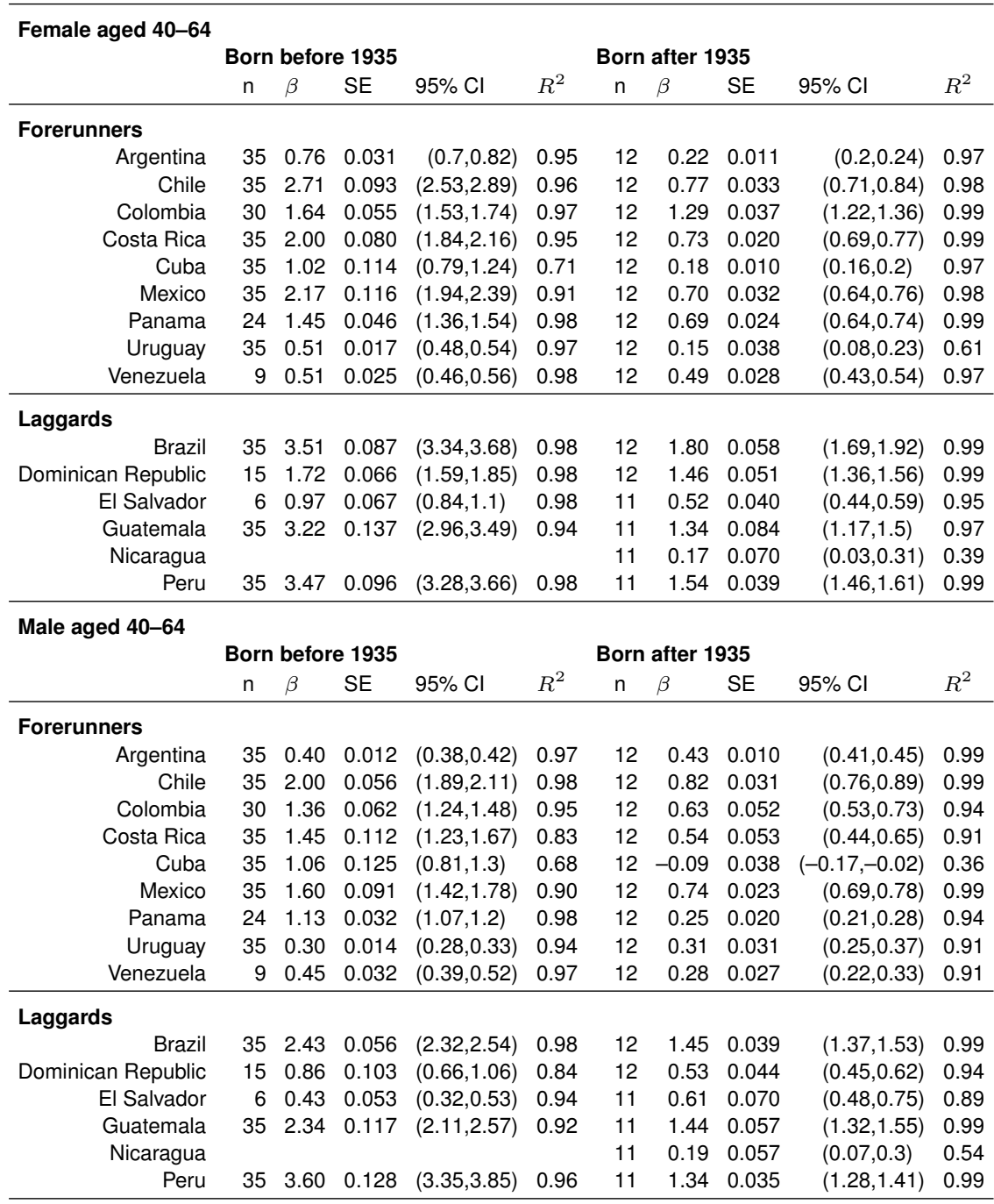

Note: Coefficients were estimated only when more than five cohorts were available. 
Table 4: $\quad$ Estimated regression coefficients from a linear mixed model of the log of adult cohort mortality as a function of childhood mortality fitted separately by sex and country's state of demographic transition for ages 40-64

\begin{tabular}{|c|c|c|c|c|}
\hline \multicolumn{5}{|l|}{ Females aged 40-64 } \\
\hline $\begin{array}{l}\text { Model } \\
\text { components }\end{array}$ & $\begin{array}{l}\text { Unconditional } \\
\text { (a) }\end{array}$ & $\begin{array}{l}\text { Conditional on } \\
\text { year of birth } \\
\text { (b) }\end{array}$ & $\begin{array}{l}\text { Unconditional } \\
\text { (a) }\end{array}$ & $\begin{array}{l}\text { Conditional on } \\
\text { year of birth } \\
\text { (b) }\end{array}$ \\
\hline \multicolumn{5}{|l|}{ Fixed effects } \\
\hline $\begin{array}{l}\hat{\gamma}_{00} \\
\hat{\gamma}_{01}=\text { Born after } 1935 \\
\text { Model for slope }\end{array}$ & $-0.674^{\star \star \star}$ & $\begin{array}{l}-0.205 \\
-0.972^{\star \star \star}\end{array}$ & 0.438 & $\begin{array}{c}1.269^{* *} \\
-1.522^{* * *}\end{array}$ \\
\hline $\begin{array}{l}\hat{\gamma}_{10} \\
\hat{\gamma}_{11}=\text { Born after } 1935\end{array}$ & $1.009^{* * *}$ & $\begin{array}{r}1.418^{\star \star *} \\
-0.840^{\star \star} \\
\end{array}$ & $1.785^{\star * *}$ & $\begin{array}{r}2.599^{\star \star \star} \\
-1.483^{\star \star} \\
\end{array}$ \\
\hline Random effects: & Variance & Variance & Variance & Variance \\
\hline $\begin{array}{l}\text { Intercept } \\
\text { Slope }\end{array}$ & $\begin{array}{l}0.606^{* * *} \\
0.513^{* * *}\end{array}$ & $\begin{array}{l}0.387^{* * *} \\
0.351^{* * *}\end{array}$ & $\begin{array}{l}1.645^{* * *} \\
1.328^{* * *}\end{array}$ & $\begin{array}{l}1.109^{* * *} \\
0.790^{* * *}\end{array}$ \\
\hline $\begin{array}{l}\text { Percent of the variance } \\
\text { Intercept } \\
\text { Slope }\end{array}$ & $\begin{array}{l}\text { xplained in para } \\
- \\
-\end{array}$ & $\begin{array}{l}\text { meters by adding } \\
36.198 \\
31.548\end{array}$ & $\begin{array}{l}\text { ar of birth } \\
- \\
-\end{array}$ & $\begin{array}{l}32.572 \\
40.535\end{array}$ \\
\hline \multicolumn{5}{|l|}{ Males aged $40-64$} \\
\hline $\begin{array}{l}\text { Model } \\
\text { components }\end{array}$ & $\begin{array}{l}\text { Unconditional } \\
\text { (a) }\end{array}$ & $\begin{array}{l}\text { Conditional on } \\
\text { year of birth } \\
\text { (b) }\end{array}$ & $\begin{array}{l}\text { Unconditional } \\
\text { (a) }\end{array}$ & $\begin{array}{l}\text { Conditional on } \\
\text { year of birth } \\
\text { (b) }\end{array}$ \\
\hline \multicolumn{5}{|l|}{ Fixed effects } \\
\hline $\begin{array}{l}\hat{\gamma}_{00} \\
\hat{\gamma}_{01}=\text { Born after } 1935 \\
\text { Model for slope }\end{array}$ & $-0.548^{\star \star *}$ & $\begin{array}{l}-0.215 \\
-0.693^{\star \star \star}\end{array}$ & 0.252 & $\begin{array}{c}0.779^{*} \\
-0.974^{* * *}\end{array}$ \\
\hline $\begin{array}{l}\hat{\gamma}_{10} \\
\hat{\gamma}_{11}=\text { Born after } 1935\end{array}$ & $0.762^{\star \star \star}$ & $\begin{array}{l}1.089^{\star \star *} \\
-0.671^{\star *}\end{array}$ & $1.389^{* \star *}$ & $\begin{array}{l}1.964^{\star \star \star} \\
-1.058\end{array}$ \\
\hline Random effects: & Variance & Variance & Variance & Variance \\
\hline $\begin{array}{l}\text { Intercept } \\
\text { Slope }\end{array}$ & $\begin{array}{l}0.336^{\star \star \star *} \\
0.310^{\star \star \star}\end{array}$ & $\begin{array}{l}0.225^{\star \star \star} \\
0.205^{\star \star \star}\end{array}$ & $\begin{array}{l}0.845^{\star \star \star} \\
1.074^{\star \star \star}\end{array}$ & $\begin{array}{l}0.645^{\star \star \star} \\
0.843^{\star \star \star}\end{array}$ \\
\hline \multicolumn{5}{|c|}{ Percent of the variance explained in parameters by addding year of birth } \\
\hline $\begin{array}{l}\text { Intercept } \\
\text { Slope }\end{array}$ & - & $\begin{array}{l}33.014 \\
33.876\end{array}$ & $\begin{array}{l}- \\
-\end{array}$ & $\begin{array}{l}23.723 \\
21.535\end{array}$ \\
\hline
\end{tabular}

Note: Level 1: $\ln \left(\mathrm{M}_{i j}(x, t)\right)=a_{0 j}+\beta_{1 j} \ln \left(\mathrm{M}_{i j}(0, t)\right)+r_{i j}$;

Level 2: $a_{0 j}=\gamma_{00}+\gamma_{01}\left(\right.$ Born after 1935) $+u_{0 j}$;

$\beta_{1 j}=\gamma_{10}+\gamma_{11}$ (Born after 1935) $+u_{1 j}$.

${ }^{* * *} p<0.001,{ }^{* *} p<0.01,{ }^{*} p<0.05$. See text for a full description of the model parameters. 
Verhulst, Beltrán-Sánchez \& Palloni: Impact of delayed effects on human old-age mortality

Table 5: $\quad$ Years of gains in life expectancy gained and foregone at age 60 and approximate $95 \%$ CI with bootstrap computations

\begin{tabular}{|c|c|c|c|c|c|c|}
\hline \multicolumn{7}{|l|}{ Female } \\
\hline & \multicolumn{4}{|c|}{ Proportionate gains ratios } & \multicolumn{2}{|c|}{ Years gains foregone } \\
\hline & (1) & (2) & (3) & (4) & (5) & (6) \\
\hline & $\begin{array}{c}\text { Born before } \\
1935\end{array}$ & $\begin{array}{c}\text { Born after } \\
1935\end{array}$ & $(2) /(1)$ & $95 \% \mathrm{Cl}$ for $(3)$ & $\begin{array}{c}\text { Born after } \\
1935\end{array}$ & $95 \% \mathrm{Cl}$ \\
\hline \multicolumn{7}{|l|}{ Forerunners } \\
\hline Argentina & 1.083 & 1.090 & 1.006 & $(1,1.012)$ & 0.686 & $(0.682,0.69)$ \\
\hline Chile & 1.492 & 1.178 & 0.790 & $(0.764,0.815)$ & 0.874 & $(0.856,0.891)$ \\
\hline Colombia & 1.313 & 1.134 & 0.864 & $(0.832,0.897)$ & 0.798 & $(0.776,0.821)$ \\
\hline Costa Rica & 1.336 & 1.114 & 0.834 & $(0.784,0.883)$ & 0.828 & $(0.794,0.862)$ \\
\hline Cuba & 1.236 & 0.982 & 0.795 & $(0.742,0.847)$ & 0.868 & $(0.832,0.904)$ \\
\hline Mexico & 1.377 & 1.015 & 0.737 & $(0.699,0.775)$ & 0.936 & $(0.91,0.962)$ \\
\hline Panama & 1.254 & 1.051 & 0.839 & $(0.824,0.854)$ & 0.823 & $(0.812,0.833)$ \\
\hline Uruguay & 1.062 & 1.064 & 1.002 & $(0.988,1.016)$ & 0.689 & $(0.679,0.698)$ \\
\hline Venezuela & 1.094 & 1.058 & 0.967 & $(0.95,0.983)$ & 0.714 & $(0.702,0.725)$ \\
\hline \multicolumn{7}{|l|}{ Laggards } \\
\hline Brazil & 1.626 & 1.336 & 0.822 & $(0.795,0.849)$ & 0.839 & $(0.821,0.858)$ \\
\hline Dominican Rep. & 1.188 & 1.112 & 0.936 & $(0.891,0.981)$ & 0.737 & $(0.706,0.768)$ \\
\hline El Salvador & 1.090 & 1.130 & 1.037 & $(1.002,1.072)$ & 0.666 & $(0.641,0.69)$ \\
\hline Guatemala & 1.597 & 1.334 & 0.835 & $(0.783,0.887)$ & 0.826 & $(0.79,0.862)$ \\
\hline Peru & 2.054 & 1.307 & 0.636 & $(0.583,0.689)$ & 1.084 & $(1.048,1.121)$ \\
\hline \multicolumn{7}{|l|}{ Male } \\
\hline & \multicolumn{4}{|c|}{ Proportionate gains ratios } & \multicolumn{2}{|c|}{ Years gains foregone } \\
\hline & (1) & (2) & (3) & (4) & (5) & (6) \\
\hline & $\begin{array}{c}\text { Born before } \\
1935\end{array}$ & $\begin{array}{c}\text { Born after } \\
1935\end{array}$ & $(2) /(1)$ & $95 \% \mathrm{Cl}$ for (3) & $\begin{array}{c}\text { Born after } \\
1935\end{array}$ & $95 \% \mathrm{Cl}$ \\
\hline \multicolumn{7}{|l|}{ Forerunners } \\
\hline Argentina & 1.164 & 1.045 & 0.898 & $(0.884,0.911)$ & 0.769 & $(0.76,0.778)$ \\
\hline Chile & 1.719 & 1.166 & 0.678 & $(0.639,0.718)$ & 1.017 & $(0.99,1.044)$ \\
\hline Colombia & 1.388 & 1.294 & 0.932 & $(0.906,0.959)$ & 0.740 & $(0.722,0.758)$ \\
\hline Costa Rica & 1.492 & 1.157 & 0.776 & $(0.743,0.809)$ & 0.890 & $(0.867,0.912)$ \\
\hline Cuba & 1.226 & 1.037 & 0.845 & $(0.8,0.891)$ & 0.816 & $(0.785,0.848)$ \\
\hline Mexico & 1.543 & 1.150 & 0.745 & $(0.697,0.793)$ & 0.926 & $(0.893,0.959)$ \\
\hline Panama & 1.336 & 1.148 & 0.859 & $(0.838,0.88)$ & 0.803 & $(0.789,0.818)$ \\
\hline Uruguay & 1.107 & 1.030 & 0.931 & $(0.914,0.947)$ & 0.742 & $(0.73,0.753)$ \\
\hline Venezuela & 1.107 & 1.103 & 0.996 & $(0.981,1.011)$ & 0.693 & $(0.682,0.703)$ \\
\hline \multicolumn{7}{|l|}{ Laggards } \\
\hline Brazil & 2.018 & 1.433 & 0.710 & $(0.669,0.752)$ & 0.971 & $(0.942,1)$ \\
\hline Dominican Rep. & 1.411 & 1.339 & 0.949 & $(0.916,0.983)$ & 0.727 & $(0.704,0.75)$ \\
\hline El Salvador & 1.214 & 1.110 & 0.914 & $(0.883,0.945)$ & 0.755 & $(0.733,0.777)$ \\
\hline Guatemala & 1.904 & 1.307 & 0.687 & $(0.622,0.751)$ & 1.005 & $(0.961,1.049)$ \\
\hline Peru & 2.002 & 1.361 & 0.680 & $(0.638,0.721)$ & 1.015 & $(0.986,1.044)$ \\
\hline
\end{tabular}

Note: Columns 1 and 2 are for proportionate gains in life expectancy at age 60 associated with a $1 \%$ decline in child mortality in cohorts born before and after 1935. Column 3 is for the ratios of proportionate gains of cohorts born before and after 1935 . Column 4 is for the $95 \%$ confidence intervals of estimates in column 3 (approximated using delta method; see Appendix 2). Column 5 is for the number of years of life expectancy at age 60 foregone by the cohorts born after 1935. Column 6 is for the $95 \%$ confidence interval of quantities in column 6 (approximated using delta method; see Appendix 2). 


\section{Prediction 2.2}

Prediction 2.2 is about the within-cohort relation between early childhood mortality and the slope of adult mortality rates. According to this prediction, we expect that more recent birth cohorts, those most vulnerable to the influence of delayed effects, should experience downward shifts in the adult mortality slope conditional on their childhood mortality experiences. A corollary leads to a placebo-type test: The rate of senescence in birth cohorts highly primed for the expression of delayed effects should be smaller than expected in populations that are less primed to express delayed effects.

To implement the test, we rely on mortality patterns in five European countries included in the Human Mortality Database, estimate model 2, and then use these estimates to predict expected Gompertz slopes in each of the birth cohorts in LAC, given their levels of child mortality. The expectation is that the predicted slope will be larger than the observed one. Global prediction 2.2 is that differences between predicted and observed values will be larger for cohorts born after 1935 and in countries with a mortality decline that was faster, later, and more dependent on medical technology.

Figures S-3 in the supplement I are plots of the secular relation between child mortality and Gompertz slopes in LAC and the HMD countries. To test for sensitivity to right censoring of cohorts, each of the three figures employs a different set of adult age groups to compute the slope (40-59, 40-64, and 40-69). Table 6 displays a full set of statistics for Model 2 in LAC from regressions that use Gompertz slopes estimated with age group 40-64. Similar inferences follow from results for age groups 40-59 and 40-69 in Tables S-3 and in Figures S-4 in Supplemental Material I. The panel for LAC shows that coefficients are equally likely to be negative or positive. In contrast, in all five HMD countries the slopes are negative, and birth cohorts that experience lower risks of child mortality also experience more accelerated aging. The negative association between early life mortality and Gompertz slopes is consistent with previous evidence from European cohorts born in both the $19^{\text {th }}$ century and the early $20^{\text {th }}$ century (Beltrán-Sánchez, Crimmins, and Finch 2012). A comparison of cohorts born before and after 1935 in LAC suggests that in all but three of 14 possible contrasts, the slopes are, as expected by prediction 2.2, attenuated and substantially so, with reduction ratios ranging from about 1.1 to 4.5 in males and females alike. However, the magnitude of the attenuation is somewhat larger in forerunner than in laggard countries, a finding inconsistent with global prediction 2.2. Although the comparison between the two periods is less meaningful in the European context, it is interesting to note that there the relation between early mortality and senescence sharpens over time - becoming more negative - rather than attenuating as it does in LAC.

The placebo test requires computation of expected Gompertz slopes in cohorts born in LAC using the relations observed in the European countries. Table 7 displays proportionate differences between predicted (from an equation estimated for Sweden) and observed values of Gompertz slopes for cohorts born before and after 1935 using all 
three age groups. Figure 6 plots predicted versus observed values of Gompertz slopes using relations estimated in all five HMD countries, whereas Figure 7 contains box plots of the magnitude of proportionate differences for ages 40-59, 40-64, and 40-69. ${ }^{8}$

While not perfect, the agreement with prediction 2.2 is quite strong. First, proportionate differences tend to increase in absolute values in more than $90 \%$ of the birth cohorts, irrespective of the age group contributing to estimates of Gompertz slopes. In countries where the oldest cohorts are characterized by negative values, the younger cohorts become associated with less negative or positive differences. And in countries where the older birth cohorts are characterized by positive differences, the younger cohorts become associated with much larger positive values. Thus, there seems to be a strong push toward an increase in the difference between what would be expected under the Swedish mortality regime and what is observed, just as prediction 2.2 would have it. Second, differences for the cohorts born more recently tend to be higher in laggard than in forerunner countries. Thus, all five countries with the lowest differences are forerunners and only three of them (Chile, Colombia, and Mexico) display values larger than at most two laggard countries (Mexico). This is consistent with global prediction 2.2.

Finally, Figure 6 reveals two additional features in the placebo test. First, differences between predicted and observed Gompertz slopes behave similarly, irrespective of which HMD country we choose as benchmark. Second, the contrasts produced when using different adult age groups to compute Gompertz slopes are reasonably concordant and lead to similar inferences (see also Table 7).

\footnotetext{
${ }^{8}$ We compute predicted Gompertz's slopes for all LAC cohorts, irrespective of whether or not their child mortality is within the range of observed values in HMD countries. This is unlikely to distort comparisons as it affects a few cohorts in LAC born after 1935 whose child mortality was experienced by countries in HMD before 1935 .
} 
Figure 6: Predicted and observed Gompertz slopes for cohorts born before and after 1935. Predicted Gompertz-slopes in LAMBdA are computed from Equation (2) for HMD cohorts born before and after 1935

Cohorts born before 1935

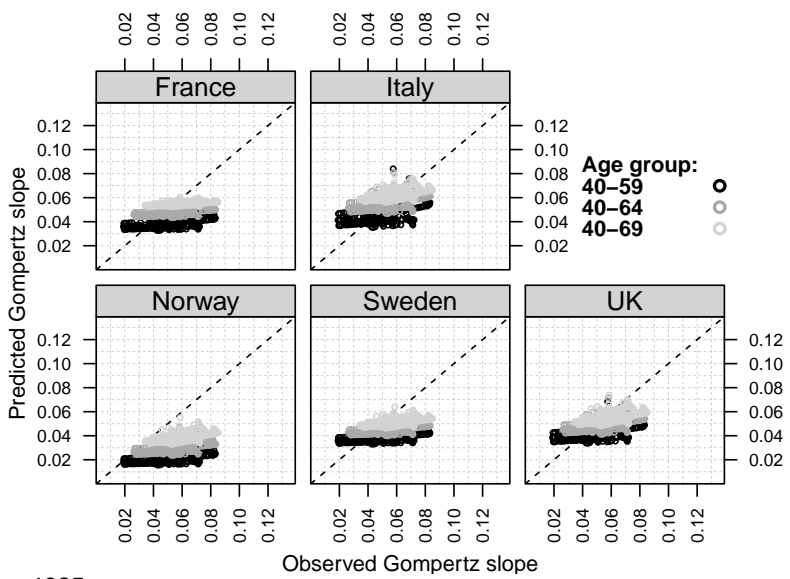

Cohorts born after 1935

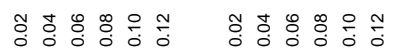
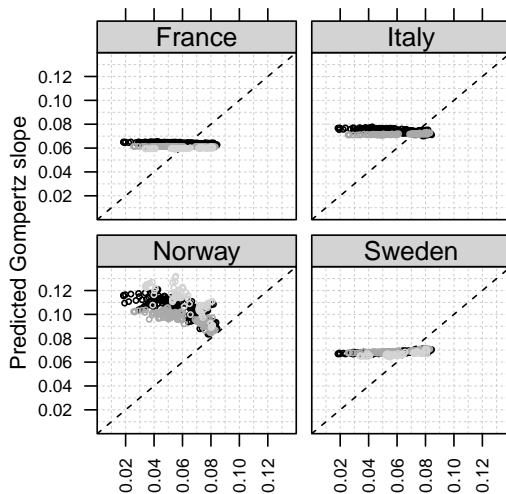

$-0.12$

- 0.10 Age group:

0.08 Age 59

0.06 40-64

0.04
$-40-69$

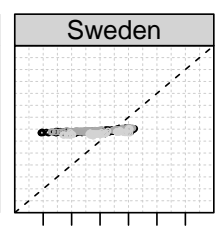

0.02

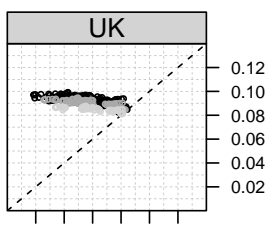

Observed Gompertz slope 
Figure 7: Box plots of proportionate differences (x100) between predicted and observed Gompertz slopes

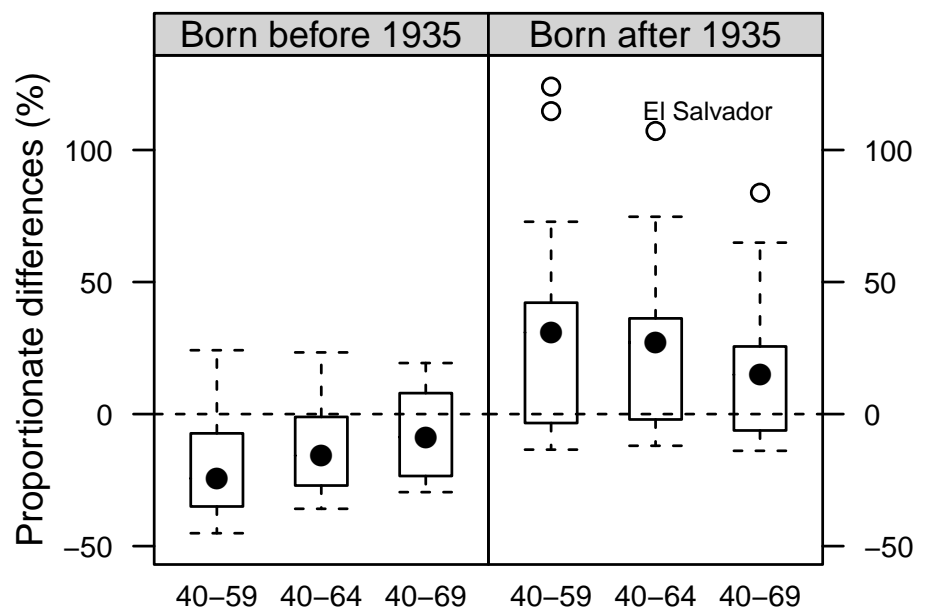

Note: Proportionate difference is computed as $100^{\star}$ (predicted slope - observed slope)/observed slope. 
Table 6: Estimated regression coefficients of the regression

$\ln \left(\mathbf{G S}_{i}(40,64)\right)=\lambda_{i}+\theta_{i} * \ln \left(\mathbf{M}_{i}(0,4)\right)+\sigma_{i}$ by country $(i)$, sex, and cohort year of birth; $G S(40,64)$ stands for Gompertz-slope between ages $40-64 ; M(0,4)$ corresponds to cohort mortality rate at age $0-4$

\begin{tabular}{|c|c|c|c|c|c|c|c|c|c|c|}
\hline \multicolumn{11}{|l|}{ Female aged $40-64$} \\
\hline & \multicolumn{3}{|c|}{ Born before 1935} & \multicolumn{7}{|c|}{ Born after 1935} \\
\hline & $\mathrm{n}$ & $\theta$ & SE & $95 \% \mathrm{Cl}$ & $R^{2}$ & $\mathrm{n}$ & $\theta$ & SE & $95 \% \mathrm{Cl}$ & $R^{2}$ \\
\hline \multicolumn{11}{|l|}{ Forerunners } \\
\hline Argentina & 35 & -0.93 & 0.172 & $(-1.26,-0.59)$ & 0.47 & 12 & -0.46 & 0.016 & $(-0.49,-0.43)$ & 0.99 \\
\hline Chile & 35 & -0.59 & 0.170 & $(-0.92,-0.25)$ & 0.26 & 12 & -0.59 & 0.064 & $(-0.71,-0.46)$ & 0.90 \\
\hline Colombia & 30 & -0.88 & 0.073 & $(-1.03,-0.74)$ & 0.84 & 12 & 0.45 & 0.073 & $(0.31,0.59)$ & 0.79 \\
\hline Costa Rica & 35 & -1.56 & 0.110 & $(-1.77,-1.34)$ & 0.86 & 12 & -0.04 & 0.106 & $(-0.25,0.16)$ & 0.02 \\
\hline Cuba & 35 & -1.14 & 0.096 & $(-1.33,-0.95)$ & 0.81 & 12 & 0.32 & 0.028 & $(0.26,0.37)$ & 0.93 \\
\hline Mexico & 35 & -1.71 & 0.119 & $(-1.95,-1.48)$ & 0.86 & 12 & -0.95 & 0.030 & $(-1.01,-0.89)$ & 0.99 \\
\hline Panama & 24 & -0.02 & 0.105 & $(-0.23,0.18)$ & 0.00 & 12 & -0.58 & 0.064 & $(-0.71,-0.46)$ & 0.89 \\
\hline Uruguay & 35 & -0.25 & 0.039 & $(-0.33,-0.17)$ & 0.55 & 12 & -0.04 & 0.043 & $(-0.13,0.04)$ & 0.10 \\
\hline Venezuela & 9 & -0.49 & 0.030 & $(-0.55,-0.43)$ & 0.97 & 12 & 0.00 & 0.007 & $(-0.01,0.02)$ & 0.04 \\
\hline \multicolumn{11}{|l|}{ Laggards } \\
\hline Brazil & 35 & 3.10 & 0.214 & $(2.68,3.52)$ & 0.86 & 12 & -1.46 & 0.116 & $(-1.68,-1.23)$ & 0.94 \\
\hline Dominican Republic & 15 & 1.13 & 0.363 & $(0.42,1.84)$ & 0.43 & 12 & -1.72 & 0.097 & $(-1.91,-1.53)$ & 0.97 \\
\hline El Salvador & 6 & -0.50 & 0.083 & $(-0.66,-0.34)$ & 0.90 & 11 & -0.62 & 0.055 & $(-0.73,-0.52)$ & 0.94 \\
\hline Guatemala & 35 & -0.63 & 0.202 & $(-1.03,-0.23)$ & 0.23 & 11 & -1.05 & 0.155 & $(-1.36,-0.75)$ & 0.84 \\
\hline Nicaragua & & & & & & 11 & -0.48 & 0.088 & $(-0.65,-0.3)$ & 0.76 \\
\hline Peru & 35 & -1.93 & 0.391 & $(-2.7,-1.17)$ & 0.43 & 11 & -0.24 & 0.244 & $(-0.72,0.24)$ & 0.10 \\
\hline \multicolumn{11}{|l|}{ Male aged 40-64 } \\
\hline & \multicolumn{3}{|c|}{ Born before 1935} & \multicolumn{7}{|c|}{ Born after 1935} \\
\hline & $\mathrm{n}$ & $\theta$ & SE & $95 \% \mathrm{Cl}$ & $R^{2}$ & $\mathrm{n}$ & $\theta$ & SE & $95 \% \mathrm{Cl}$ & $R^{2}$ \\
\hline \multicolumn{11}{|l|}{ Forerunners } \\
\hline Argentina & 35 & -0.22 & 0.117 & $(-0.45,0.01)$ & 0.10 & 12 & -0.23 & 0.032 & $(-0.29,-0.17)$ & 0.84 \\
\hline Chile & 35 & 0.25 & 0.127 & $(0,0.5)$ & 0.11 & 12 & -0.65 & 0.037 & $(-0.72,-0.57)$ & 0.97 \\
\hline Colombia & 30 & -0.45 & 0.076 & $(-0.6,-0.31)$ & 0.56 & 12 & 1.30 & 0.094 & $(1.12,1.48)$ & 0.95 \\
\hline Costa Rica & 35 & -1.36 & 0.225 & $(-1.8,-0.91)$ & 0.52 & 12 & -0.19 & 0.072 & $(-0.33,-0.05)$ & 0.40 \\
\hline Cuba & 35 & -0.71 & 0.069 & $(-0.84,-0.57)$ & 0.76 & 12 & 0.22 & 0.036 & $(0.15,0.29)$ & 0.79 \\
\hline Mexico & 35 & -0.87 & 0.128 & $(-1.12,-0.62)$ & 0.59 & 12 & -0.71 & 0.057 & $(-0.82,-0.6)$ & 0.94 \\
\hline Panama & 24 & 0.02 & 0.061 & $(-0.1,0.14)$ & 0.00 & 12 & -0.60 & 0.050 & $(-0.7,-0.51)$ & 0.94 \\
\hline Uruguay & 35 & -0.16 & 0.045 & $(-0.25,-0.07)$ & 0.28 & 12 & -0.01 & 0.047 & $(-0.1,0.08)$ & 0.01 \\
\hline Venezuela & 9 & 0.28 & 0.028 & $(0.22,0.33)$ & 0.93 & 12 & -0.09 & 0.034 & $(-0.16,-0.02)$ & 0.40 \\
\hline \multicolumn{11}{|l|}{ Laggards } \\
\hline Brazil & 35 & 1.41 & 0.120 & $(1.17,1.64)$ & 0.81 & 12 & 0.23 & 0.058 & $(0.12,0.35)$ & 0.62 \\
\hline Dominican Republic & 15 & 0.35 & 0.074 & $(0.2,0.49)$ & 0.63 & 12 & 0.01 & 0.078 & $(-0.15,0.16)$ & 0.00 \\
\hline El Salvador & 6 & 2.06 & 0.330 & $(1.41,2.7)$ & 0.91 & 11 & -1.47 & 0.520 & $(-2.49,-0.45)$ & 0.47 \\
\hline Guatemala & 35 & -1.23 & 0.160 & $(-1.54,-0.91)$ & 0.64 & 11 & 0.28 & 0.594 & $(-0.89,1.44)$ & 0.02 \\
\hline Nicaragua & & & & & & 11 & -0.45 & 0.195 & $(-0.83,-0.07)$ & 0.38 \\
\hline Peru & 35 & -1.86 & 0.310 & $(-2.47,-1.25)$ & 0.52 & 11 & 1.01 & 0.198 & $(0.62,1.4)$ & 0.74 \\
\hline
\end{tabular}

Note: A Gompertz-slope is separately estimated for each country-cohort-sex from the model $M(x)=a * \exp (b * x)$, for $x \in[40,64]$. Coefficients were estimated only when more than five cohorts were available. 
Verhulst, Beltrán-Sánchez \& Palloni: Impact of delayed effects on human old-age mortality

Table 7: Proportionate differences between predicted (counterfactual) and observed values of birth cohorts' Gompertz slopes for ages 40-59, 40-64, and 40-69

\begin{tabular}{|c|c|c|c|c|c|}
\hline \multicolumn{6}{|l|}{ Female } \\
\hline \multicolumn{2}{|c|}{$40-59$} & \multicolumn{2}{|c|}{$40-64$} & \multicolumn{2}{|c|}{$40-69$} \\
\hline Country & $\begin{array}{l}\text { Prop. } \\
\text { Diff. }\end{array}$ & Country & $\begin{array}{c}\text { Prop. } \\
\text { Diff. (\%) }\end{array}$ & Country & $\begin{array}{c}\text { Prop. } \\
\text { Diff. (\%) }\end{array}$ \\
\hline Peru & 24.18 & Peru & 23.35 & Peru & 19.32 \\
\hline Mexico & 15.50 & Mexico & 13.62 & Mexico & 15.52 \\
\hline Guatemala & 0.59 & Guatemala & 7.35 & Guatemala & 9.38 \\
\hline Costa Rica & -7.31 & El Salvador & -1.08 & El Salvador & 7.93 \\
\hline Chile & -16.43 & Costa Rica & -9.19 & Chile & -4.35 \\
\hline El Salvador & -21.98 & Chile & -10.02 & Dom. Rep. & -6.61 \\
\hline Colombia & -23.56 & Dom. Rep. & -15.10 & Brazil & -7.54 \\
\hline Dom. Rep. & -25.21 & Brazil & -16.33 & Costa Rica & -9.91 \\
\hline Brazil & -29.04 & Colombia & -18.50 & Colombia & -13.52 \\
\hline Panama & -31.22 & Panama & -24.25 & Panama & -16.71 \\
\hline Uruguay & -35.00 & Uruguay & -27.06 & Argentina & -23.46 \\
\hline Argentina & -38.29 & Argentina & -30.08 & Uruguay & -23.84 \\
\hline Cuba & -42.11 & Cuba & -35.35 & Venezuela & -27.76 \\
\hline Venezuela & -45.13 & Venezuela & -35.87 & Cuba & -29.57 \\
\hline \multicolumn{2}{|l|}{ Male } & \multirow{2}{*}{\multicolumn{2}{|c|}{$40-64$}} & \multirow{2}{*}{\multicolumn{2}{|c|}{$40-69$}} \\
\hline \multicolumn{2}{|c|}{$40-59$} & & & & \\
\hline Country & $\begin{array}{l}\text { Prop. } \\
\text { Diff. }\end{array}$ & \multicolumn{2}{|c|}{ ( } & \multicolumn{2}{|c|}{$\begin{array}{cc}\text { Prop. } \\
\text { Diff. }(\%)\end{array}$} \\
\hline El Salvador & 124.02 & El Salvador & 107.22 & El Salvador & 83.85 \\
\hline Guatemala & 114.73 & Guatemala & 74.73 & Guatemala & 64.93 \\
\hline Colombia & 72.84 & Colombia & 37.38 & Mexico & 26.58 \\
\hline Ecuador & 66.47 & Nicaragua & 36.29 & Brazil & 25.60 \\
\hline Mexico & 42.18 & Mexico & 36.19 & Nicaragua & 18.94 \\
\hline Nicaragua & 42.01 & Brazil & 34.90 & Chile & 17.02 \\
\hline Brazil & 37.53 & Peru & 27.30 & Colombia & 14.90 \\
\hline Chile & 30.93 & Chile & 27.03 & Peru & 13.31 \\
\hline Peru & 30.90 & Dom. Rep. & 20.82 & Panama & 4.15 \\
\hline Dom. Rep. & 28.54 & Panama & 15.70 & Argentina & -6.22 \\
\hline Panama & 13.46 & Venezuela & 0.33 & Costa Rica & -7.33 \\
\hline Venezuela & 3.71 & Argentina & -4.44 & Uruguay & -12.65 \\
\hline Costa Rica & -3.40 & Costa Rica & -4.99 & Cuba & -13.92 \\
\hline Argentina & -4.73 & Cuba & -8.48 & & \\
\hline Cuba & -6.57 & Uruguay & -12.01 & & \\
\hline Paraguay & -7.98 & & & & \\
\hline Uruguay & -13.47 & & & & \\
\hline
\end{tabular}

Note: Proportionate difference is computed as $100^{*}$ (predicted slope - observed slope)/observed slope. 


\section{Summary of findings, limitations, and the road ahead}

The implications of $\mathrm{DOHaD}$ conjectures for aggregate population patterns of human disease, disability, mortality, and aging are poorly understood. In this paper we scratch the surface of what could be a much larger field of research as we only investigate relations involving mortality and ignore morbidity and disability. This is our first effort to sort out consequences of $\mathrm{DOHaD}$ for aggregate population patterns and, as such, it has strengths and weaknesses.

\subsection{Summary of results}

We employ a model of relations between early conditions and delayed effects to formulate two predictions that apply to aggregate adult mortality patterns in populations primed for the expression of delayed effects. We define empirical conditions under which such effects could be observed and test predictions with a long time series of cohort mortality in LAC. A somewhat conservative conclusion from the empirical evidence we gathered is that observed patterns are reasonably consistent with expectations from the model's predictions, and that LAC patterns of adult mortality do reveal the footprints that delayed effects are predicted to leave on adult mortality patterns. Indeed, within bounds of uncertainty we disclose explicitly, we find that more recently born cohorts experience both deceleration in survival gains at older ages and distortions in their age patterns, including reduction of the association between child mortality and adult mortality and the attenuation of the rate of aging at older ages.

The empirical evidence we retrieved, however, is not water-tight, depends on parameter estimates that are somewhat fragile, and - importantly - can be accounted for with alternative explanations. We address each of these issues below.

\subsection{Limitations}

Our analyses have several shortcomings. First, the model and predictions rest on the simplifying assumption that all mechanisms invoked by variants of $\mathrm{DOHaD}$ induce delayed effects that can be bundled together and studied jointly. This assumption is likely to be incorrect, but it is not immediately clear how its violation could bias our estimates of total or gross impacts.

Second, the empirical tests we rely on are based on fictitious, not real, cohort life tables. This is unavoidable as there are no life tables for real cohorts in LAC and only a handful (for birth cohorts born before 1925 in countries with registration systems) in HMD. Construction of life tables for fictitious birth cohorts relies on chaining together yearly mortality rates for single age groups. And while under ideal conditions these 
estimates closely approximate the mortality trajectory of a real cohort, there can be inconsistencies. To ascertain that inconsistencies do not bias our results, we launched a verification experiment using HMD. The results of this experiment, documented in Supplementary Material II, confirm two regularities. First, life tables for real and fictitious cohorts lead to estimates of mortality patterns that can be characterized by virtually the same parameters and (b) the relation between those parameters in a life table for the real cohort is closely matched by the same relation in the life table of the fictitious cohorts. An added bonus from the experiment that came as a surprise to us is this: Estimates of Gompertz slopes with censored cohorts (with mortality experiences between ages 40$59,40-64$, and 40-69) are strongly correlated $\left(R^{2}>.90\right)$ with Gompertz slopes using uncensored mortality experiences (ages 40-90). Furthermore, the relations between estimates from uncensored adult mortality experiences and early mortality are reproduced very closely by relations between censored adult experiences and child mortality.

Third, our empirical tests did not account for confounding that was a result of the intrusion of differential improvements in medical technologies that target chronic illnesses related to delayed effects. If, for example, improvements in screening and treatment of T2D - one of the key chronic illnesses associated with adverse early conditions - outpaced improvements associated with chronic diseases that are not related to delayed effects, we would underestimate the importance of the latter and underplay their influence.

Fourth, the empirical tests rely on imperfect data. Due to right censoring of adult mortality experiences in LAC region, we have limited statistical power to test null hypotheses because the number of birth cohorts available for analysis plunges precisely during periods when the adult consequences of delayed effects are more likely to be felt.

Significant right censoring is also a limitation that precludes the use of powerful analytic techniques, such as Age-Period-Cohort models, that support stronger inferences.

Fifth, the classification of countries relies on a blunt tool, namely, the combination of an indicator of timing of mortality decline with a categorization of countries by past mortality experiences. Strictly speaking, the distinction between forerunners and laggards is one that should apply to subgroups or individuals within countries. But we are working with countries and nations and do not have historical data for regions as, for example, the European Fertility Study did. Admitting this weakness, however, should not blind us to the fact that the two criteria we use (timing of introduction of modern medical technology and timing of onset of mortality decline) are unlikely to be off by much. In fact, the year(s) of onset of full dissemination of antibiotics and vaccines cannot exceed 1935-1940. There might be heterogeneity within countries because the timing of full dissemination varies, particularly in populations whose mortality decline begins after 1935-1940. But this heterogeneity is at worst modest. On the other hand, we know with high precision when mortality began to decline in each country and, therefore, in this case at least, we have full information. Using a simple classification of countries, rather than 
continuous variables, could generate noise, but it is highly improbable that it will cause more extensive damage.

Finally, throughout, we ignored distortions that could be caused by changes in mortality due to accidents and violence, causes of death that have a peculiar profile in LAC countries. Mortality due to violence and accidents is concentrated among males in the age interval $15-40$ or so. Over the last ten to fifteen years, these causes have become less important, except in countries like Mexico, Venezuela, and El Salvador. In what ways can these trends affect our conclusions? First, road traffic accidents in Latin American disproportionally involve individuals who drive vehicles and are (or were up until recently at least) a selected group, perhaps less exposed to deleterious conditions early in life. A decrease in these deaths will swell the population that is less likely to have experienced adverse early conditions, thus working against our hypothesis. On the other hand, deaths due to violence disproportionally occur in subpopulations that are more likely to have been exposed to poor early conditions, and a decline in these deaths will have the opposite effect from that of deaths due to violence and will thus operate in favor of the conjecture. The net result is uncertain, and to sort out the exact direction of the bias one would need to use full information on causes of death.

\subsection{Future research}

Future research in this area could proceed along a number of avenues. First, in this paper we explored only the implications for one outcome, mortality patterns, when it is clear that both morbidity and disability and, therefore, healthy life expectancy, must be heavily affected as well. Generalizations to include morbidity and disability will require different formal models and information on health outcomes of diverse nature.

Second, an important area of study is the potentially aggravating impacts on adult health outcomes of mismatches between prenatal and postnatal environments. This is a significant piece of the puzzle, as described by the Predictive Adaptive Response (PAR) variant of $\mathrm{DOHaD}$. Ignoring it, as we did here, underplays the role of delayed effects, especially in countries where delayed effects are expected to be largest.

Any future research on this problem will face an unavoidable obstacle, which we may refer to as "Popper's curse," namely, failure to falsify the theory is not equivalent to successful verification. Falsifying DOHaD conjectures can only produce evidence to reject them, not to confirm them. Concordance between the two predictions and empirical findings is not invoked here to argue the validity of a claim; it is only an indication of absence of inconsistency rather than material proof of the adequacy of the theory. Because the empirical patterns we detect in LAC could be the result of mechanisms other than those embedded in a regime of delayed effects, more robust falsification necessitates different research strategies than the ones we followed here. One of them is analyses 
of full-information case studies of populations (in countries or regions) that underwent contrasting experiences. These studies should cover all dimensions required for proper tests of DET, including empirical indicators of mismatching and the nature of mortality decline. A second research strategy is to pursue studies of adult illnesses and mortality patterns with multiple birth cohorts exposed to heterogeneous early experiences and in populations with different regimes of secular mortality decline, including timing of onset, nature of mortality determinants, and size of mismatching. Third, comparative studies of older populations that include rich information about early conditions as well as detailed information on chronic illnesses, disability, and mortality, and fielded in populations with disparate epidemiological and mortality regimes, will offer a more robust empirical platform to test the aggregate population implications of DET.

\section{Acknowledgments}

This work was supported by the National Institute on Aging via research project grants R01-AG016209, R03-AG015673, R01-AG018016, R37-AG025216, R01-AG056608, and R01-AG052030), by a Fogarty International Center award for Global Research Training in Population Health, D43-TW001586, and by core grants to the Center for Demography and Ecology, R24-HD047873, and to the Center for Demography of Health and Aging, P30-AG017266), at the University of Wisconsin-Madison. In addition, support was obtained from Grant P2C-HD041022 from the National Institute of Child Health and Human Development to the California Center for Population Research at UCLA. 


\section{References}

Almond, D. (2006). Is the 1918 influenza pandemic over? Long-term effects of in utero influenza exposure in the post-1940 US population. Journal of Political Economy 114(4): 672-712. doi:10.1086/507154.

Barker, D.J.P. (1998). Mothers, babies, and health in later life. Edinburgh: Churchill Livingstone.

Barker, D.J.P. (2012). Development origins of chronic disease. Public Health 126(3): 185-189. doi:10.1016/j.puhe.2011.11.014.

Bateson, P., Barker, D.J.P., Clutton-Brock, T., Deb, D., D’Udine, B., Foley, R.A., Gluckman, P., Godfrey, K., Kirkwood, T., Lahr, M.M., McNamara, J., Metcalfe, N.B., Monaghan, P., Spencer, H.G., and Sultan, S.E. (2004). Developmental plasticity and human health. Nature 430(6998): 419-421. doi:10.1038/nature02725.

Bateson, P. and Gluckman, P. (2011). Plasticity, robustness, development and evolution. Cambridge: Cambridge University Press. doi:10.1017/CBO9780511842382.

Beltrán-Sánchez, H., Crimmins, E.M., and Finch, C.E. (2012). Early cohort mortality predicts the rate of aging in the cohort: A historical analysis. Journal of Developmental Origins of Health and Disease 3(5): 380-386. doi:10.1017/S2040174412000281.

Bengtsson, T. and Lindström, M. (2012). Childhood misery and disease in later life: The effects on mortality in old age of hazards experienced in early life, southern Sweden, 1760-1894. Population Studies 54(3): 263-277. doi:10.1080/713779096.

Cao-Lei, L., Massart, R., Suderman, M.J., Machnes, Z., Elgbeili, G., Laplante, D.P., Szyf, M., and King, S. (2014). DNA methylation signtaures triggered by prenatal maternal stress exposure to a natural disaster: Project Ice Storm. PLoS One 9(9): e107653. doi:10.1371/journal.pone.0107653.

Costa, D. (2000). Understanding the twentieth-century decline in chronic conditions among older men. Demography 37(1): 53-72. doi:10.2307/2648096.

Crimmins, E.M. and Finch, C.E. (2006). Infection, inflammation, height, and longevity. Proceedings of the National Academy of Sciences of the United States of America 103(2): 498-503. doi:10.1073/pnas.0501470103.

Derrick, V.P.A. (2006). Observations on (1) errors of age in the population statistics of England and Wales, and (2) the changes in mortality indicated by the national records. Journal of the Institute of Actuaries 58(2): 117-159. doi:10.1017/ S0020268100031474.

Elo, I.T. and Preston, S.H. (1992). Effects of early-life conditions on adult mortality: A 
review. Population Index 58(2): 186-212. doi:10.2307/3644718.

Finch, C.E. and Crimmins, E.M. (2004). Inflammatory exposure and historical changes in human life-spans. Science 305(5691): 1736-1739. doi:10.1126/science.1092556.

Fogel, R.W. (2004). The escape from hunger and premature death. Cambridge: Cambridge University Press.

Fong, I.W. (2000). Emerging relations between infectious disease and coronary artery disease and atherosclerosis. Canadian Medical Journal 163(1): 49-56.

Forsdahl, A. (1987). Living conditions in childhood and subsequent development of risk factors for artheriosclerotic heart disease: The cardiovascular survey in Finnmark 1974-1975. Journal of Epidemiology and Community Health 32: 34-37. doi:10.1136/ jech.32.1.34.

Forsdahl, A. (2002). Commentary: Childhood deprivation and adult mortality. International Journal of Epidemiology 31(2): 308. doi:10.1093/ije/31.2.308.

Fridlizius, G. (1989). The deformation of cohorts: Nineteenth century mortality decline in a generational perspective. Scandinavian Economic History Review and Economy and Society 37(3): 3-17. doi:10.1080/03585522.1989.10408152.

Frost, W.H. (1939). The age selection of mortality from tuberculosis in successive decades. American Journal of Hygiene 39(3): 91-96. doi:10.1093/oxfordjournals. aje.a118570.

Gluckman, P.D., Buklijas, T., and Hanson, M.A. (2016). The developmental origins of health and diseases (DOHaD) concept: Past, present, and future. In: Rosenfeld, C. (ed.). The epigenome and developmental origins of health and disease. London: Elsevier: 1-15. doi:10.1016/B978-0-12-801383-0.00001-3.

Gluckman, P.D. and Hanson, M.A. (2005). The fetal matrix: Evolution, development and disease. Cambridge: Cambridge University Press.

Gluckman, P.D. and Hanson, M.A. (2006). The develpmental origins of health and disease. Cambridge: Cambridge University Press. doi:10.1017/CBO9780511544699.

Godfrey, K., Lillycrop, K., Burdge, G., Gluckman, P.D., and Hanson, M.A. (2007). Epigenetic mechanisms and the mismatch concept of the developmental origins of health and disease. Pediatrics Research 61(5.2): 5R-10R. doi:10.1203/pdr. 0b013e318045bedb.

Hales, C.N. and Baker, D.J. (2001). The thrifty phenotype hypothesis. British Medical Bulletin 60(1): 5-20. doi:10.1093/bmb/60.1.5.

Kermack, W.O., McEndrick, A.G., and McKinlay, P.L. (1934). Death rates in Great 
Britain and Sweden: Expression of specific mortality rates as product of two factors, and some consequences thereof. Journal of Hygiene 34(3): 433-457. doi:10.1017/ S0022172400043230.

Kuh, D. and Ben-Shlomo, Y. (1997). A life course approach to chronic disease epidemiology. Oxford: Oxford University Press.

Kuzawa, C.W. and Eisenberg, D.T.A. (2014). The long reach of history: Intergenerational and transgenerational pathways to plasticity in human longevity. In: Weinstein, M. and Lane, M. (eds.). Sociality, hierarchy, health: Comparative biodemography. Washington, D.C.: National Research Council Press: 65-94.

Lucas, A. (1991). Programming by early nutrition in man. In: Bock, G. and Cole, T. (eds.). The childhood environment and adult disease. Chichester: John Wiley: 38-55.

Lumey, L.H., Terry, M.B., Delgado-Cruzata, L., Liao, Y., Wang, Q., Susser, E., McKeague, I., and Santella, R.M. (2012). Adult global DNA methylation in relation to prenatal nutrition. International Journal of Epidemiology 41(1): 116-123. doi:10.1093/ ije/dyr137.

McEwen, B.S. (1998). Protective and damaging effects of stress mediators: Allostasis and allostatic load. The New England Journal of Medicine 338: 171-179. doi:10.1056/ NEJM199801153380307.

Meaney, M.J. (2001). Maternal care, gene expression, and the transmission of individual differencesin stress reactivity across generations. Annual Review of Neuroscience 24: 1161-1192. doi:10.1146/annurev.neuro.24.1.1161.

Meaney, M.J. (2010). Epigenetics and the biological definition of gene $\mathrm{x}$ environment interactions. Child Development 81(1): 41-79. doi:10.1111/j.1467-8624.2009.01381.x.

Palloni, A. and Beltrán-Sánchez, H. (2016). Demographic consequences of Barker frailty. In: Schoen, R. (ed.). Dynamic demographic analysis. New York: Springer: 147-176. doi:10.1007/978-3-319-26603-9_8.

Palloni, A. and Beltrán-Sánchez, H. (2017). Discrete Barker frailty and warped older age mortality dynamics. Demography 54(2): 655-671. doi:10.1007/s13524-017-0548-4.

Palloni, A., Beltrán-Sánchez, H., and Pinto, G. (2016). Two centuries of mortality decline in Latin America: From hunger to longevity. Paper presented at XI Congreso de la Associación de Demografía Histórica (ADEH), Cádiz, Spain, June 21-24, 2016.

Palloni, A. and Pinto, G. (2011). Adult mortality in Latin America and the Caribbean. In: Rogers, R. and Crimmins, E. (eds.). International handbook of adult mortality. New York: Springer: 101-132. doi:10.1007/978-90-481-9996-9_5.

Palloni, A. and Souza, L. (2013). The fragility of the future and the tug of the past: 
Longevity in Latin America and the Caribbean. Demographic Research 29(21): 543578. doi:10.4054/DemRes.2013.29.21.

Palloni, A. and Wyrick, R. (1981). Mortality decline in Latin America: Changes in the structure of causes of death, 1950-1975. Social Biology 28(3-4): 187-216. doi:10.1080/19485565.1981.9988458.

Preston, S.H. (1980). Causes and consequences of mortality decline in less developed countries during the twentieth century. In: Easterlin, R.A. (ed.). Population and economic change in developing countries. Chicago: University of Chicago Press: 289360.

Preston, S.H. and van de Walle, E. (1978). Urban French mortality in the nineteeth century. Population Studies 32(2): 275-297. doi:10.1080/00324728.1978.10410715.

Rosenfeld, C.S. (2008). The developmental origins of health and diseases (DOHaD) concept: Past, present, and future. London: Elsevier.

Scrimshaw, N.S. (1997). Nutrition and health from womb to tomb. Food and Nutrition Bulletin 18(1): 1-19. doi:10.1177/156482659701800101.

Scrimshaw, N.S. and SanGiovanni, J.P. (1997). Synergism of nutrition, infection, and immunity: An overview. The American Journal of Clinical Nutrition 66(2): 464S477S. doi:10.1093/ajcn/66.2.464S.

Sika-Paotonu, D., Beaton, A., Raghu, A., Steer, A., and Carapetis, J. (1980). Acute rheumatic fever and rheumatic heart disease. In: Ferretti, J., Stevens, D., and Fischetti, V. (eds.). Streptococcus pyogenes: Basic biology to clinical manifestations. Oklahoma City: University of Oklahoma Health Sciences Center: 771-826.

United Nations (2017). World population prospects. New York: DESA/Population Division.

Vaupel, J.W. and Missov, T. (2014). Unobserved population heterogeneity: A review of formal relationships. Demographic Research 31(22): 659-686. doi:10.4054/DemRes. 2014.31.22.

Vickers, M.H. (2014). Developmental programming and transgenerational transmission of obesity. Annals of Nutrition and Metabolism 64(S1): 26-34. doi:10.1159/ 000360506.

Yajnik, C.S. (2014). Transmission of obesity-adiposity and related disorders from the mother to the baby. Annals of Nutrition and Metabolism 64(S1): 8-17. doi:10.1159/ 000362608 . 


\section{Appendix 1: Key results from a formal model of delayed effects}

In previous work (Palloni and Beltrán-Sánchez 2016, 2017) we show that age patterns of mortality in a regime that combines delayed effects and secular mortality decline can be concisely described. In particular, rates of changes with age and time, as well as time trends in the associations between indicators of mortality at different ages, are captured with simple expressions.

We assume that the force of mortality at age $y$ of the $i^{t h}$ individual in a birth cohort born $t$ years after the onset of mortality decline is given by

$$
\mu_{i}(y, t)=\mu_{s}(y) k(t) E_{y t}(\delta, R)
$$

where $\mu_{s}(y)$ is a baseline mortality pattern shared by the entire population, $k(t)=$ $\exp (-\gamma t)^{9}$ is a multiplier that expresses mortality of birth cohort $t$ relative to the baseline mortality pattern at $t=0$, and $E_{y t}(\delta, R)$ is the expected value of a (strictly positive, continuously distributed) random trait $\delta$ for susceptibility to delayed effects with relative mortality risks equal to $R>1$. In what follows we will refer to $\mu_{i}(y, t)=$ $\mu_{s}(y) k(t) E_{y t}(\delta, R=1)$ as the 'background' force of mortality, that is, the force of mortality that would prevail if there were no delayed effects, e.g., $R=1$. Three results follow from (1).

\section{Rate of mortality change over time and in adult ages}

The instantaneous rate of change of adult mortality over time is:

$$
\frac{\partial \ln (\bar{\mu}(y, t))}{\partial t}=\frac{\partial \ln (k(t))}{\partial t}\left[1-k(t) \bar{\Lambda}(y, t, R)\left(C V_{y t}(\delta, R)\right)^{2}\right]
$$

where $\bar{\mu}(y, t)$ is the average (observed) mortality rate at age $y$ for the birth cohort born $t$ years after the onset of mortality decline, $\bar{\Lambda}(y, t, R)$ is the integrated force of mortality up to age $y$ for the same cohort, and $C V_{y t}(\delta, R)$ is the coefficient of variation of the random susceptibility trait $(\delta)$ at age $y$ for the birth cohort born $t$ years after the mortality decline. by

In addition, the instantaneous age-related rate of change of adult mortality is given

$$
\frac{\partial \ln (\bar{\mu}(y, t))}{\partial y}=\frac{\partial \ln \left(\mu_{s}(y)\right)}{\partial y}-\mu_{s}(y) \bar{\Lambda}(y, t)\left(C V_{y t}(\delta, R)\right)^{2} .
$$

Since $k(t) \bar{\Lambda}(y, t)\left(C V_{y t}(\delta, R)\right)^{2}$ can potentially attain values higher than 1 , adult mortality decline will slow down and could even increase (expression (2)). In addition,

\footnotetext{
${ }^{9}$ The assumption of an exponential decline of the force of mortality is harmless and considerably simplifies the algebra.
} 
the observed slope of adult mortality will be lower than the slope in the baseline mortality pattern (expression (3)).

\section{Association between mortality markers at different ages}

Since the magnitude of the attenuation of the rate of decline at adult ages will change nonmonotonically across cohorts, delayed effects will induce correlations between a cohort's early mortality and (i) the levels of adult mortality and (ii) the rate of change of adult mortality with age. In a simplified model where standard frailty $\delta$ is distributed as $\Gamma(r, \lambda)$ and excess mortality associated with delayed effects is $R>1$, the following results apply:

1. The relation between the average force of mortality between an early age $x$ and an adult age $\nu$ older than a critical age $Y$ is given by

$$
\bar{\mu}(v, t)=\bar{\mu}(x, t) \frac{\lambda+\exp (-\gamma t) \Lambda_{s}(x)}{\left.\lambda+\exp (-\gamma t) \Lambda_{s}(\nu, R)\right) \varphi_{s}(v, x, \varepsilon)}
$$

where $\Lambda_{s}(v, R)=\int_{0}^{Y} \mu_{s}(y) d y+R \int_{Y}^{v} \mu_{s}(y) d y$ and $\Lambda_{s}(\nu)=\int_{0}^{v} \mu_{s}(y) d y$ are the integrated baseline hazards up to age $v$ with and without delayed effects, respectively. The quantity $\varphi_{s}(v, x, \varepsilon)$ is a factor that transforms $\mu_{s}(x)$ into $\mu_{s}(v)$ in a one parameter-model life table, and $\varepsilon$ is an indicator of the levels of mortality in the baseline pattern. ${ }^{10}$ Because the factor that multiplies the quantity $\varphi_{s}(v, x, \varepsilon)$ in expression (4) is less than 1, an OLS estimate of the regression coefficient of $\ln (\bar{\mu}(v, t))$ on $\ln (\bar{\mu}(x, t))$ estimated over a set of cohorts will yield a downwardly biased estimate of the population parameter of interest, namely, $\varphi_{s}(v, x, \varepsilon)$. The absolute value of the bias will increase with $R$ and age and decrease over time. As a consequence, the covariance between measures of child mortality and adult mortality should drop for more recently born cohorts

2. Assume that the adult baseline mortality rates follow an exponential law with slope $\beta$, that random frailty is $\Gamma(r, \lambda)$, and excess mortality associated with delayed effects is $R>1$. One can show that the estimate of the slope $\beta$ will be the regression coefficient in the following expression

$$
\bar{\mu}(y, t)=\mu_{s}\left(x^{*}\right) \exp \left(\beta\left(y-x^{*}\right)\right)\left(\frac{r}{\lambda+\exp (-\gamma t) \Lambda_{s}(y, R)}\right)
$$

where $x^{*}>Y$ is the age of onset of the exponential law of mortality. It follows from first principles that the OLS estimate of $\beta$ from the above expression will

\footnotetext{
${ }^{10}$ In any of the four Coale-Demeny model patterns the unique parameter (mortality level) is life expectancy at age 10 .
} 
be downwardly biased, the bias will be larger when $R$ is larger, and will decrease as $t \rightarrow \infty$. The consequence of this is that $\beta$ should decline over time in cohorts influenced by the secular mortality decline and, in addition, the covariance between a measure of child mortality and $\beta$ should be positive. 


\section{Appendix 2: Hypothetical survival gains foregone due to delayed effects}

\section{Approximation to expected gains foregone}

We estimate the following relation:

$$
\ln M(x, t)=\alpha+\beta \ln M(0, t)
$$

where $M(x, t)$ is the mortality rate in an adult age group $(x, x+k)$ for a cohort born in year $t$ and $M(0, t)$ is the mortality rate in the age group $0-4$ experienced by the same cohort. According to the formal model, when there are delayed effects, the value of $\beta$ should decrease for more recently born cohorts as the inflow of individuals more susceptible to express delayed effects at older ages increases. This swelling of susceptibility will initially increase mortality rates in the youngest adult ages relative to the oldest, thus lowering the value of $\beta$. Suppose that one compares cohorts born before and after 1935 , and each is characterized by values of $\alpha$ and $\beta$. The key is to think of $\beta$ as a proportionate reduction of a cohort's adult mortality rate - in the age interval $(x, x+k)$ - that would prevail given proportionate changes in a cohort mortality at age $0-4$ when delayed effects are weak (cohorts born before 1935, $\beta_{1}$ ) and strong (cohorts born after $\left.1935, \beta_{2}\right)$. Suppose we observe the process during 20 years, a time interval during which $M(0, t)$ is changing at the rate of .01 per year. This means that the reduction in the adult mortality rate $M(x, t)$ is given by $\exp \left(\left(\beta_{1} / 100\right) * 20\right)$ when there are no delayed effects and $\exp \left(\left(\beta_{2} / 100 * 20\right)\right.$ if there are delayed effects. If these magnitudes hold for all ages older than $x$, and if the entropy of the survival curve in the background mortality pattern is approximately .69 , the foregone gains of life expectancy at age 60 are $\pi(x) \sim .69 * \exp \left(\left(\beta_{1} / 100\right) * 20\right)-.69 * \exp \left(\left(\beta_{2} / 100\right) * 20\right)=.69 * \exp \left(\left(\beta_{1}-\beta_{2}\right) * .20\right)$. When $\beta_{2}<\beta_{1}$ this quantity is (approximately) the expected number of years of life after age $x$ that would be added in the absence of delayed effects or, alternatively, the gains that will not be realized due to the presence of delayed effects.

The approximation to the value of $\pi$ depends on two assumptions. The first is that the value of $\beta$ is a constant for all ages older than $x$. The second is about the entropy

of the survival curve, namely the quantity $E(x)=\int_{x} \ln \left(S_{x}(y)\right) S_{x}(y) d x / \int_{x} S_{x}(y) d x$, where $S_{x}(y)$ is the conditional probability of surviving from age $x$ to age $y>x$. There is a relation between proportionate changes in the force of mortality at all ages older than $x$ and the change induced in life expectancy at that age, $e(x)$. The relation is mediated by the entropy of the survival curve above than age, $E(x)$. This relation establishes that a $1 \%$ increase (decrease) in the force of mortality at all ages above $x$ translates into a $E(x)<1 \%$ decrease (increase) in $e(x)$. Since what is of interest to us are the effects on old age mortality, the value if $E(x)=.69$ was computed numerically using $x=60$ and the Coale-Demeny female West model life table with a life expectancy at birth of 
50 years. An illustration is as follows: suppose the values of $\beta_{1}=.900$ and $\beta_{2}=.200$. The gains foregone should be given by $\pi \sim .69 *\left(\exp (.900 * .20)-\exp \left(.200^{*} .20\right)\right) \sim .16$ of what could have been gained. Thus, if the average value of $E(60)$ hovers around 18 years - as it currently is in most LAC countries - the $E(60)$ implied by a value of $\beta=.9$ in the absence of delayed effects is $18 * 1.19=21.4$ years but only $18 * 1.041=18.73$ when there are delayed effects. This represents gains foregone of around $15 \%$ (close enough to $16 \%$ as implied by the expression). These magnitudes will of course vary with the value chosen for $x$. For our purposes, however, this is unimportant since we are trying to offer a more transparent interpretation of the estimates of the $\beta^{\prime} s$ (with and without delayed effects) rather than compute exact values of gains or losses in life expectancy implied by them.

\section{Approximation to the variance of gains foregone}

A general version of the approximation to the proportionate gains/losses of life expectancy at age $x$ imputed to absence/presence of delayed effects and embedded in the expression relating $M(x, t)$ and $M(0, t)$ is

$$
\pi(x) \sim E(x) * \exp \left(\left(\beta_{1}-\beta_{2}\right) * .20\right)
$$

where $\mathrm{E}(\mathrm{x})$ is the entropy of the survival curve most suitable to represent the age pattern of mortality of various cohorts. The approximation only works if:

(i) $\left(\beta_{1}-\beta_{2}\right)$ is small,

(ii) the relation between $M(x, t)$ and $M(0, t)$ specified above holds for all ages above $x$, and

(iii) the period of observation is 20 years.

The variance of $\pi(x)$ can be approximated by the Delta-method as $\operatorname{Var}(\pi(x)) \sim$ $.04 * E(x)^{2}\left(\operatorname{Var}\left(\beta_{1}\right)+\operatorname{Var}\left(\beta_{2}\right)\right)$. 
Verhulst, Beltrán-Sánchez \& Palloni: Impact of delayed effects on human old-age mortality 